\title{
FRACTURE TOUGHNESS OF ALLOY 690 AND EN52 WELD IN AIR AND WATER
}

C. M. Brown and W. J. Mills

U. S. Department of Energy Contract DE-AC11-98PN38206

June 1999

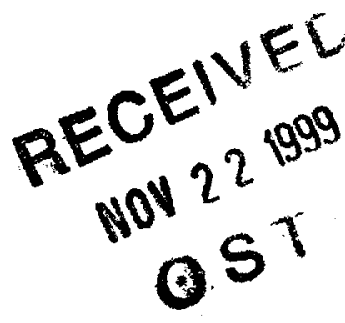

\section{NOTICE}

This report was prepared as an account of work sponsored by the United States Government. Neither the United States, nor the United States Department of Energy, nor any of their employees, nor any of their contractors, subcontractors, or their employees, makes any warranty, express or implied, or assumes any legal liability or responsibility for the accuracy, completeness or usefulness of any information, apparatus, product or process disclosed, or represents that its use would not infringe privately owned rights. 


\section{DISCLAIMER}

This report was prepared as an account of work sponsored by an agency of the United States Government. Neither the United States Government nor any agency thereof, nor any of their employees, make any warranty, express or implied, or assumes any legal liability or responsibility for the accuracy, completeness, or usefulness of any information, apparatus, product, or process disclosed, or represents that its use would not infringe privately owned rights. Reference herein to any specific commercial product, process, or service by trade name, trademark, manufacturer, or otherwise does not necessarily constitute or imply its endorsement, recommendation, or favoring by the United States Government or any agency thereof. The views and opinions of authors expressed herein do not necessarily state or reflect those of the United States Government or any agency thereof. 


\section{DISCLAIMER}

Portions of this document may be illegible in electronic image products. Images are produced from the best available original document. 


\title{
FRACTURE TOUGHNESS OF ALLOY 690 AND EN52 WELD IN AIR AND WATER
}

C. M. Brown and W. J. Mills

\begin{abstract}
The effect of low and high temperature water with high hydrogen on the fracture toughness of Alloy 690 and its weld, EN52, was characterized using elastic-plastic $J_{1 c}$ methodology. While both materials display excellent fracture resistance in air and elevated temperature $\left(>93^{\circ} \mathrm{C}\right)$ water, a dramatic degradation in toughness is observed in $54^{\circ} \mathrm{C}$ water. The loss of toughness is associated with a hydrogen-induced intergranular cracking mechanism where hydrogen is picked up from the water. Comparison of the cracking behavior in low temperature water with that for hydrogen-precharged specimens tested in air indicates that the critical local hydrogen content required to cause low temperature embrittlement is on the order of 120 to $160 \mathrm{ppm}$. Loading rate studies show that the cracking resistance is significantly improved at rates above $\sim 1000 \mathrm{MPa} \vee \mathrm{m} / \mathrm{h}$ because there is insufficient time to produce grain boundary embrittlement. Electron fractographic examinations were performed to correlate cracking behavior with microstructural features and operative fracture mechanisms.
\end{abstract}




\section{INTRODUCTION}

Alloy 690 is an attractive candidate for replacing Alloy 600 components in primary water reactor (PWR) applications when stress corrosion cracking (SCC) is a design concern. Indeed, testing to date has shown that this material is immune to high temperature SCC in primary and pure water regardless of microstructure and heat treatment condition. ${ }^{(1-5)}$ The composition of Alloy 690 is similar to that for Alloy 600, except that its chromium content has been doubled from about $15 \%$ to $30 \%$. As a result of its superior SCC resistance, Alloy 690 has been used to replace Alloy 600 pressurizer heater sleeves and instrument nozzles, as well as steam generator tubes. ${ }^{(6,7)}$

Alloy 690 is typically welded using either EN82H or EN52 weld filler metals. EN82H, which is also used to weld Alloy 600 components, is rather susceptible to high temperature SCC. While the SCC resistance for EN52 is far superior to that for EN82 ${ }_{r}^{(1)}$ its inferior weldability has limited its use.

The expected failure mechanisms for welded Alloy 600 and Alloy 690 components involve crack initiation and propagation due to SCC or corrosion fatigue, followed by stable or unstable tearing when a critical crack size is reached. This study focuses on the final step in the cracking process involving stable and unstable fracture. While these materials exhibit excellent toughness in air, fracture properties are degraded in low temperature water. ${ }^{(1)}$ Extensive testing of Alloy 600 and $\mathrm{EN82H}$ welds showed that these materials have exceptionally high fracture toughness in air and high temperature water. ${ }^{(8)}$ in low temperature water, Alloy 600 showed a modest decrease in toughness, but retained sufficient cracking resistance to avoid fracture concerns. By contrast, EN82H welds tested in low temperature $\left(<149^{\circ} \mathrm{C}\right)$ water exhibited a dramatic reduction in toughness as $J_{\mathrm{IC}}$ and tearing moduli were reduced by one to two orders of magnitude. The reduction in toughness was associated with a hydrogen embrittlement mechanism whereby hydrogen from the water weakened grain boundaries and promoted planar slip, which localized strain concentrations along grain boundaries.

A preliminary study ${ }^{(1)}$ indicated that Alloy 690 and EN52 weld metal also exhibit a significant loss of toughness in low temperature water. Thus, the purpose of this work is to determine the effects of low and high temperature water with high hydrogen on the cracking 
resistance of these materials. Fracture properties were determined in $24^{\circ}$ to $338^{\circ} \mathrm{C}$ air and hydrogenated water using elastic-plastic $J_{I C}$ methodology due to their ductile response. Scanning electron microscopy (SEM) examinations of fracture surfaces were performed to correlate trends in fracture toughness behavior with operative cracking mechanisms. The role of hydrogen embrittlement in degrading fracture properties was evaluated by comparing the cracking behavior in low temperature water with that for hydrogen-precharged specimens tested in low temperature air and water. 


\section{MATERIALS AND EXPERIMENTALPROCEDURE}

\section{Iest Materials}

The Alloy 690 test materials included a $76 \mathrm{~mm}$ diameter bar (Heat A) and a $64 \mathrm{~mm}$ diameter bar (Heat B). Both heats were tested in the as-received condition, which involved a $1074^{\circ} \mathrm{C}$ anneal for 5 minutes with an air cool, followed by a $718^{\circ} \mathrm{C}$ thermal treatment for 10 hours with an air cool. The EN52 welds were fabricated by two manufacturers [" $\mathrm{B}$ " and " $\mathrm{C}$ "-vendor identification is consistent with Reference (8)] using a manual gas-tungsten-arc (GTA) weld process. Welds manufactured by Vendor "B" joined Alloy 690 to EN82 clad A516 Grade 60 steel using a $100 \%$ argon shield gas. Welds manufactured by Vendor " $\mathrm{C}$ " joined two Alloy 690 plates and used either a $100 \%$ argon shield gas (" $\left.\mathrm{C} 1^{\mathrm{I}}\right)$ or a $98 \% / 2 \%$ argon/hydrogen shield gas ("C2") for improved weldability. All welds were tested in the as-welded condition. Chemical compositions and mechanical properties for the test materials are provided in Tables 1 and 2.

Representative microstructures for the test materials are shown in Figure 1a. The Alloy 690 heats exhibit a uniform grain size with a mean grain diameter of about $75 \mu \mathrm{m}$. Grain boundaries are decorated with rather fine chromium-rich $M_{23} C_{6}$ carbides and there is evidence of ghost boundaries of carbides.

The EN52 welds have well-defined grain boundaries separating colonies of similarly oriented dendrites, as shown in Figure 1b. Grain boundaries are decorated with small titanium-rich $\mathrm{MC}$ and chromium-rich $\mathrm{M}_{23} \mathrm{C}_{6}$ carbides. Intermediate size carbides are also observed in the interdendritic regions. These interdendritic carbides sometimes pin the grain boundaries.

\section{Fracture Toughness Testing}

Fracture tests were performed on precracked compact tension (CT) specimens that had a width (W) of $30.5 \mathrm{~mm}$, a thickness (B) of $15.2 \mathrm{~mm}$ and $20 \%$ side grooves. The weld specimens were tested in the longitudinal orientation, where the notch was parallel to the welding direction. 
Specimens were tested in air and water using servo-electric feedback-controlled systems that were operated in displacement control. Low loading rates, $4 \mathrm{MPa} / \mathrm{m} / \mathrm{h}$ at $54^{\circ} \mathrm{C}$ and 0.4 to $2 \mathrm{MPa} / \mathrm{m} / \mathrm{h}$ at $338^{\circ} \mathrm{C}$, were used to allow sufficient time for environmental effects to occur. Loading rates for a few $54^{\circ} \mathrm{C}$ water tests were also varied between 0.4 and $26,000 \mathrm{MPa} / \mathrm{m} / \mathrm{h}$ to evaluate rates effects on environmental cracking behavior.

In accordance with multiple-specimen $J_{1 C}$ test procedures, specimens were unloaded when the target displacement was reached, heat tinted to discolor the crack extension region, and subsequently fatigued apart so the amount of crack extension ( $\Delta a$ ) could be measured by the ASTM E1737-96 nine-point measurement method. Because external load cells were used to measure test load in autoclave tests, the seal friction load was measured and subtracted from the load measurement at the beginning of the test. Load-line displacement values for each specimen were computed from external LVDT displacement measurements using the correction procedures outlined in Reference (8) to subtract out extraneous load-train displacements. The corrected load versus load-line displacement data were used to compute $\mathrm{J}$ in accordance with ASTM E1737-96.

The multispecimen $J-R$ curve method was used to establish $J_{I C}$ values, because the periodic unload/reload cycles associated with the unloading compliance method could possibly affect the environmental cracking behavior in water. The overall $J_{I C}$ analysis methods were patterned after ASTM E1737-96. J-R curves were constructed by plotting $\mathrm{J}$ values against the corresponding crack extension values $(\Delta \mathrm{a})$ and fitting the $\mathrm{J}-\Delta \mathrm{a}$ data with a power-law regression line. The $J_{\mathrm{I}}$ toughness was the value of $\mathrm{J}$ at the intersection of the power-law curve with the $0.2 \mathrm{~mm}$ offset blunting line:

$$
\Delta a=\frac{J}{4 \sigma_{f}}+0.2(\mathrm{~mm})
$$

where $\sigma_{f}$ is the flow strength, which is equal to the average of the yield and ultimate strength levels [i.e., $\sigma_{\mathrm{f}}=\left(\sigma_{\mathrm{YS}}+\sigma_{\mathrm{UTS}}\right) / 2$ ]. Note that the blunting line developed for high strain hardening materials, ${ }^{(9)} \mathrm{J}=4 \sigma_{f}(\Delta \mathrm{a})$, accurately estimates the apparent blunting behavior for both the wrought and weld metals. Values of the tearing modulus $(T)$, which represents a dimensionless measure of the tearing resistance after $J_{1 C}$ is exceeded, were calculated from the following equation: ${ }^{(10)}$ 


$$
T=\frac{d J}{d a} \frac{E}{\sigma_{f}^{2}}
$$

where $\mathrm{dJ} / \mathrm{da}$ is the average slope of the $\mathrm{J}-\mathrm{R}$ curve (at $\Delta \mathrm{a} \approx 1.3 \mathrm{~mm}$ ) and $E$ is the elastic modulus. For specimens that exhibited relatively little plasticity prior to the onset of environmental cracking, equivalent critical stress intensity factors $\left(K_{\mathrm{JC}}\right)$ were computed from experimental $J_{\mathrm{IC}}$ values using the equation (11)

$$
K_{J C}=\sqrt{E J_{1 C}}
$$

Although the number and spacing of J- $\Delta$ a data points do not always conform to ASTM guidelines, the $J_{1 C}$ values obtained herein are judged to be accurate estimates of the materials fracture toughness. In cases where insufficient data preclude multiple-specimen $J_{I C}$ analysis, a modified version of the normalization technique proposed by ASTM Task Group E08.08.02 was used to determine $J_{I C}$ and $T$. A detailed description of the normalization method is provided in Reference (12). In this paper, multispecimen and normalized J-R curves are represented by solid and broken lines, respectively.

\section{Iest Environment}

Flowing autoclaves were used to conduct tests in hydrogenated deaerated water at $24^{\circ}$, $54^{\circ}, 93^{\circ}, 149^{\circ}$ and $338^{\circ} \mathrm{C}$. Room temperature $\mathrm{pH}$ was 10.1 to 10.3 and the oxygen concentration typically ranged between 3 and $17 \mathrm{ppb}$. The nominal hydrogen concentration was $150 \mathrm{cc} \mathrm{H}_{2} / \mathrm{kg} \mathrm{H} \mathrm{H}_{2} \mathrm{O}$, but ranged from 140 to $180 \mathrm{cc} \mathrm{H}_{2} / \mathrm{kg} \mathrm{H} \mathrm{H}_{2} \mathrm{O}$.

\section{Hydrogen Precharging}

Hydrogen precharging was conducted in a high pressure autoclave using $99.999 \%$ pure hydrogen. As-fabricated CT specimens were first cleaned in acetone and then rinsed in alcohol before being inserted into the autoclave. To assure a uniform hydrogen distribution, precharging runs were performed at $360^{\circ} \mathrm{C}$ for 6 weeks. After precharging, the specimens were refrigerated below $0^{\circ} \mathrm{C}$ to minimize hydrogen loss. Hydrogen concentrations for at least two specimens for each test material were measured after rising load testing was complete. Chips produced by hole drilling were collected for hydrogen analysis. Care was taken not to 
heat the sample or contaminate the chips. Vacuum extraction analysis on a LECO hydrogen analyzer was performed to measure hydrogen content. The range of hydrogen concentrations was 64 to 67 ppm for Alloy 690 and 68 to 77 ppm for EN52 weld.

Eracture Toughness Testing of Hydrogen-Precharged Specimens

Hydrogen-precharged CT specimens were also tested in $24^{\circ} \mathrm{C}$ air and hydrogenated water at a nominal $\dot{K}$ of $3 \mathrm{MPa} / \mathrm{m} / \mathrm{h}$. The resulting load versus load-line displacement curves and maximum stress intensity factors $\left(K_{p_{\text {max }}}\right)$ were compared with those obtained for nonprecharged specimens tested in water to determine if hydrogen embrittlement is responsible for the degraded fracture toughness response in low temperature water. Values of $K_{\mathrm{Pmax}}$ were computed by substituting the maximum load and initial crack length into the $K$ solution in ASTM E1737-96. While $K_{\max _{\max }}$ values are not strictly valid when significant plasticity occurs (i.e., $>60$ $\mathrm{MPa} / \mathrm{m})$, they provide a relative ranking of susceptiblity to low temperature cracking.

\section{Eractographic Examinations}

Broken specimen halves were examined on an SEM to characterize the fracture surface morphology in order to compare operative cracking mechanisms for hydrogen-precharged and non-precharged specimens. 


\section{BESULTS AND DISCUSSION}

\section{Eracture of Alloy 690}

The cracking behavior for the two Alloy 690 heats in air and water is summarized in Figures 2 and 3 . It is seen that the fracture response for Heat $A$ in air is independent of temperature, so the $24^{\circ}-54^{\circ}$ and $338^{\circ} \mathrm{C}$ data were combined into a single $\mathrm{J}-\mathrm{R}$ curve yielding a $J_{I C}$ of $447 \mathrm{~kJ} / \mathrm{m}^{2}$ and $T$ of 448 . High temperature water has almost no effect on toughness as $J_{K C}$ and $T$ values are within $10 \%$ of their air counterparts. While the fracture toughness of Heat $B$ in $338^{\circ} \mathrm{C}$ water $\left(J_{I C}\right.$ of 358 and $T$ of 242$)$ is slightly less that that for Heat $A$, it still possesses excellent fracture resistance. In summary, the exceptionally high toughness values in air and high temperature water demonstrate that fracture is not an issue for Alloy 690 components under these conditions.

In $54^{\circ} \mathrm{C}$ water, there is a substantial reduction in toughness as $\mathrm{J}_{\mathrm{IC}}$ values drop to 69 and $20 \mathrm{~kJ} / \mathrm{m}^{2}$ and $T$ drops to 38 and 24. Although the $J_{I C}$ values are low, Alloy 690 exhibits some plastic deformation prior to the onset of environmental cracking and the tearing moduli indicate that modest tearing resistance is retained. Based on these findings, low temperature crack propagation (LTCP) is not viewed as a primary engineering concern for Alloy 690 . However, for critical components where the consequences of failure are a concern, fracture mechanics assessments should be performed to guard against fracture.

The cracking resistance is significantly increased when the water temperature is increased to $93^{\circ} \mathrm{C}$ (Figure 3 ) and it is fully restored at $149^{\circ} \mathrm{C}$ (Figures 2 and 3). Therefore, LTCP in Alloy 690 is an issue only at temperatures below $93^{\circ} \mathrm{C}$.

Figure 4, which summarizes displacement rate effects on LTCP behavior, shows that LTCP susceptibility is essentially rate independent below $15 \mathrm{~mm} / \mathrm{h}(\dot{K} \leq 1300 \mathrm{MPa} / \mathrm{m} / \mathrm{h})$. Within this domain, longer exposure times do not further embrittle the crack tip region. Increasing the rate to $305 \mathrm{~mm} / \mathrm{h}(26,000 \mathrm{MPa} / \mathrm{m} / \mathrm{h})$ is seen to fully restore cracking resistance. At this rate there is insufficient time to embrittle the crack tip region. Therefore, transient loading events with $\dot{K}$ greater than about $25,000 \mathrm{MPa} / \mathrm{m} / \mathrm{h}$ will not cause environmental cracking in low temperature water. 
The Alloy 690 fracture surfaces generated in air and $338^{\circ} \mathrm{C}$ water were found to be indistinguishable, as shown in Figure 5. This is consistent with the lack of an effect of elevated temperature air or water on the toughness response. Fracture surfaces are comprised of large primary dimples nucleated by broken MC carbide inclusions, smaller dimples nucleated by ghost boundary carbides and shear-stretch regions. ${ }^{\left({ }^{(8)}\right.}$ The shear-stretch morphology, which covers a large portion of the fracture surface, is characterized by a rather nondescript appearance with evidence of wavy slip lines normal to the crack growth direction and a few elongated (shear) dimples. This mechanism is associated with an alternating shear rupture process ${ }^{(13)}$ that operates when very high shear stresses develop in the ligaments between primary microvoids. The observation of welldefined dimples and serpentine slip on dimple walls and in shear-stretch regions indicates that the fracture process involves extensive plastic deformation, which accounts for the high toughness observed in air and $338^{\circ} \mathrm{C}$ water.

In $54^{\circ} \mathrm{C}$ water, intergranular cracking is dominant (Figures $6 \mathrm{a}$ and $6 \mathrm{~b}$ ). There is also limited evidence of transgranular cracked regions with poorly defined facets (Figure $6 \mathrm{c}$ ), but no evidence of dimple rupture or shear-stretch regions. High magnification of grain boundaries revealed a rough appearance, as shown in Figure $6 \mathrm{~b}$. There appears to be two causes of this rough texture: in some regions an outline of the intergranular $M_{23} C_{6}$ carbides produces the jagged structure, while in other regions the rough appearance suggests that the crack is actually propagating in the matrix immediately adjacent to grain boundaries. The intergranular cracking and transgranular faceting are believed to result from a hydrogen embrittlement mechanism, as discussed later.

\section{Fracture of EN52 Welds}

Figure 7 shows that EN52 weld metal exhibits exceptionally high toughness in air and high temperature water. The cracking response in air is independent of temperature, so the $54^{\circ}$ and $338^{\circ} \mathrm{C}$ data were pooled to establish a common J-R curve that yielded a J $\mathrm{J}_{\mathrm{C}}$ of 814 $\mathrm{kJ} / \mathrm{m}^{2}$ and $\mathrm{T}$ of 484 . High temperature water is seen to have essentially no effect on toughness, as $J_{l C}$ is $1060 \mathrm{~kJ} / \mathrm{m}^{2}$ and $T$ is 540 . These incredibly high toughness values demonstrate that fracture is not a design or operation concern for EN52 welds in air and high temperature water. 
In $54^{\circ} \mathrm{C}$ water, however, there is a dramatic reduction in toughness, as illustrated in Figures 7 and 8. For Weld "B1-b", $J_{I C}$ decreases to $37-47 \mathrm{~kJ} / \mathrm{m}^{2}$ and $T$ decreases to $31-48$. For Welds " $\mathrm{C}_{1}$ " and "C2", $\mathrm{J}_{\mathrm{K}}$ is $27 \mathrm{~kJ} / \mathrm{m}^{2}$ and $\mathrm{T}$ is only 4. These low toughness values suggest that LTCP is a concern for highly loaded EN52 welds.

Because low temperature cracking in the more embrittled welds (i.e., Welds " $\mathrm{C} 1$ " and "C2") typically initiates prior to the onset of significant plastic deformation, it is not surprising that $K_{P_{\max }}$ values, which range from 53 to $83 \mathrm{MPa} / \mathrm{m}$, are in reasonable agreeement with the $K_{\mathrm{JC}}$ value of $74 \mathrm{MPa} / \mathrm{m}$, which is computed from the experimental $\mathrm{J}_{\mathrm{IC}}$ value of $27 \mathrm{~kJ} / \mathrm{m}^{2}$. This agreement suggests that LTCP in the most embrittled welds tends to initiate at or slightly before maximum load within the linear-elastic domain. Therefore, the lower-bound $K_{p_{\max }}$ of 53 $\mathrm{MPa} / \mathrm{m}$ can be used in linear-elastic fracture mechanics assessments to estimate the limiting response.

Although EN52 weld shows a severe toughness degradation in $54^{\circ} \mathrm{C}$, its fracture resistance is considerably greater than that for $E N 82 H$ welds. Lower-bound $J_{I C}$ and $K_{p \max }$ values for EN82H welds ${ }^{(8)}$ with the same crack orientation are $14 \mathrm{~kJ} / \mathrm{m}^{2}$ and $40 \mathrm{MPa} / \mathrm{m}$, respectively.

It is noted that one of the welds manufactured by Vendor " $B$ " exhibited tremendous variability in LTCP behavior. Figure 7 shows that low temperature water has no effect on the toughness response for two specimens from Weld "B1-a", a slight effect for a third specimen and a substantial effect for the fourth. In contrast with this behavior, all three specimens machined from Weld "B1- $b$ ", which was fabricated by the same vendor using the same materials and welding parameters, were very susceptible to LTCP in $54^{\circ} \mathrm{C}$ water. The reason for this variability is unknown.

Increasing the water temperature to $93^{\circ}$ and $149^{\circ} \mathrm{C}$ significantly increases the weld's cracking resistance, as shown in Figure 8 . The high $J_{\mathrm{IC}}$ values, $218 \mathrm{~kJ} / \mathrm{m}^{2}$ at $93^{\circ} \mathrm{C}$ and $453-$ $594 \mathrm{~kJ} / \mathrm{m}^{2}$ at $149^{\circ} \mathrm{C}$, coupled with tearing moduli above 300 demonstrate that LTCP is not a concern at and above $93^{\circ} \mathrm{C}$.

Figure 9, which presents displacement rate effects on LTCP behavior, shows that the cracking response at 0.05 and $0.005 \mathrm{~mm} / \mathrm{h}(\dot{K}=4$ and $0.4 \mathrm{MPa} / \mathrm{m} / \mathrm{h})$ are the same, thereby indicating that longer exposure times do not cause additional embrittlement. Increasing the rate 
to $15 \mathrm{~mm} / \mathrm{h}(1300 \mathrm{MPa} V \mathrm{~m} / \mathrm{h})$ causes a modest increase in cracking resistance, $\mathrm{J}_{\mathrm{lc}}=133 \mathrm{~kJ} / \mathrm{m}^{2}$ and $T=70$, and at $305 \mathrm{~mm} / \mathrm{h}(26,000 \mathrm{MPa} / \mathrm{m} / \mathrm{h})$ there is a significant increase in toughness, $J_{\mathrm{IC}}=395 \mathrm{~kJ} / \mathrm{m}^{2}$ and $T=434$. At the higher rates, there is insufficient time to embrittle the crack tip region. Therefore, transient loading events with $\dot{K}$ greater than $\sim 1000 \mathrm{MPa} / \mathrm{m} / \mathrm{h}$ will not cause severe embrittlement.

The fracture surface topography for EN52 welds tested in air and $338^{\circ} \mathrm{C}$ water consists of dimples and shear-stretch markings, as shown in Figure 10. Extensive evidence of serpentine slip offsets on the fracture surface indicates that tremendous amounts of platic deformation are required to propagate the crack. This is consistent with the exceptionally high $J_{I C}$ values observed under these test conditions.

The reason why the weld exhibits greater cracking resistance than wrought Alloy 690 is the lack of large primary MC inclusions in the former. In the wrought material, the coarse inclusions fracture and nucleate large microvoids at plastic strains of just a few percent. The absence of coarse inclusions in the weld suppresses microvoid nucleation. Additional plastic energy is needed for microvoid nucleation because the smaller carbides resist fracture. Eventually, the intermediate size interdendritic carbides fail by a decohesion process, but at much greater strains.

In $54^{\circ} \mathrm{C}$ water, a fracture morphology transition from ductile tearing to intergranular cracking is responsible for the dramatic degradation in cracking resistance. The intergranular surfaces have a rather smooth and undulating appearance (Figure 11a) that reflects the dendritic morphology of the weld. At high magnification, grain boundaries are seen to be rather featureless (Figure 11b). Isolated islands containing transgranular facets are also observed, as shown at the bottom of Figure 11a. The facets tend to be steeply inclined to the overall fracture surface as they link two adjacent intergranular cracks at different elevations. This morphology indicates that unbroken ligaments are left in the wake of advancing intergranular cracks because grain boundaries in these regions resisted cracking. After the primary crack extends well beyond these ligaments, the local stresses are large enough to nucleate transgranular faceting. Macroscopic examination of fracture surfaces provides additional support for this cracking mechanism. Bright (non-heat tinted) ligaments are found within the LTCP (i.e., heat tinted) region, just behind the final crack front. This indicates that grain 
boundaries within these regions did not fail and local stresses were too low to induce crystallographic faceting.

\section{Low Temperature Cracking Mechanism}

The nature of low temperature cracking in Alloy 690 and EN52 is very similar to that observed in EN82H welds, which was shown to be associated with a hydrogen-embrittlement mechanism. To evaluate the role of hydrogen in embrittling Alloy 690 and EN52 welds, CT specimens precharged with 64-77 ppm hydrogen were tested in air in an attempt to reproduce the degree of embrittlement and cracking mechanisms found in low temperature water. Most tests were conducted at a $\dot{K}$ of $4 \mathrm{MPa} / \mathrm{m} / \mathrm{h}$ so there would be sufficient time to fully embrittle the crack tip region. A few hydrogen precharged specimens were also tested at $4 \times 10^{5}$ $\mathrm{MPa} / \mathrm{m} / \mathrm{h}$ (1-3 seconds to reach maximum load) to preclude hydrogen from diffusing and accumulating ahead of a crack. These tests are designed to help define the minimum lattice hydrogen content required to cause low temperature embrittlement. Hydrogen-precharged specimens were also tested in $54^{\circ} \mathrm{C}$ water to determine if hydrogen from the water combines with hydrogen already present to cause additional embrittlement.

Figure 12 compares $K_{\text {max }}$ for hydrogen-precharged and non-precharged specimens tested in air and low temperature water. For EN52, $K_{P_{\max }}$ for the precharged specimen tested in air, $68 \mathrm{MPa} \sqrt{\mathrm{m}}$, agrees with the range of values, 68-74 MPa $/ \mathrm{m}$, observed for non-precharged specimens tested in $54^{\circ} \mathrm{C}$ water. A similar trend is observed for Alloy 690 , whereby $K_{\text {Pmax }}$ for the precharged specimen tested in air, $53 \mathrm{MPa} \sqrt{\mathrm{m}}$, is within the range of values, 46-68 $\mathrm{MPa} \sqrt{\mathrm{m}}$, for non-precharged specimens tested in $54^{\circ} \mathrm{C}$ water. Moreover, load-displacement curves for the hydrogen-precharged specimens tested in air and non-precharged specimens tested in $54^{\circ} \mathrm{C}$ water were similar, indicating that the degree of embrittlement in low temperature water is reproduced by hydrogen-precharging.

Fractographic examinations show that cracking mechanisms operative in low temperature water are reproduced by testing precharged specimens in air. Figure 13 shows the intergranular cracking with a rough texture and transgranular faceting in precharged Alloy 690 that is reminiscent of the fracture surface appearance associated with LTCP in water (Figure 6). The only notable difference in fracture surface morphology is somewhat better defined crystallographic facets for the precharged specimens. In some regions facets have a very 
crystallographic appearance, as shown in Figure 13b, indicative of a channel fracture mechanism where localized separation occurs along intense planar slip bands. ${ }^{(14,15)}$ The presence of channel fracture in precharged specimens provides strong evidence that hydrogen promotes heterogeneous slip and lowers the cohesive strength between atoms thereby causing local separation along planar slip bands. A decohesion mechanism whereby hydrogen decreases cohesive strength and promotes failure along specific crystallographic planes was originally proposed by Steigerwald et al. ${ }^{\text {(16) }}$

The fracture surface appearance for hydrogen-precharged EN52 tested in air is identical to that for the non-precharged weld tested in $54^{\circ} \mathrm{C}$ water. Intergranular cracking is the dominant mechanism (Figure 14) and there is limited evidence of transgranular facets. Once again, the transgranular regions are steeply inclined to the overall fracture plane demonstrating that they are associated with the high shear stresses that develop in unbroken ligaments left in the wake of the advancing intergranular crack.

The observation that hydrogen-precharged specimens tested in air reproduce the degree of embrittlement and cracking mechanisms observed in low temperature water demonstrates that LTCP involves a hydrogen embrittlement mechanism. Hydrogen appears to play a dual role as it reduces the grain boundary cohesive strength and promotes planar slip which enhances strain concentrations along grain boundaries. Hydrogen also induces transgranular faceting; however, this mechanism is judged to be less important because it occurs very late in the cracking process as the large intergranular cracks coalesce.

Figure 12 also shows that testing hydrogen-precharged specimens in water produces the most severe embrittlement. This indicates that hydrogen from the water further increases the hydrogen content ahead of a crack, which further degrades toughness. Apparently, hydrogen from the water is added to the precharged hydrogen to severely weaken grain boundaries, fill traps and promote planar slip. It is also noted that the presence of hydrogen in the water minimizes the loss of precharged hydrogen from the crack tip region. The fracture surface morphologies for the precharged specimens tested in water (Figure 13c and Figure 14b) are virtually identical to their air counterparts (Figure 13a and 14a).

Rapid loading of precharged Alloy 690 fully restores $K_{p_{\max }}$ (Figure 12). Comparison of load-displacement records indicates that the ability to plastically deform is restored as well. The 
fracture surface is predominantly transgranular, consisting of shear-stretch markings and dimples. Dimple growth is stunted, however, by the onset of a faceting mechanism. Intergranular fracture is also observed, but confined to a few isolated regions.

Rapid loading of hydrogen-precharged EN52 restores $K_{\mathrm{Pmax}}$ to $100 \mathrm{MPa} / \mathrm{m}$, but comparison of load-displacement records shows that the amount of plastic deformation is less than that for non-precharged specimens tested in air. Under rapid loading conditions, the fracture surface is predominantly transgranular, consisting of dimples and poorly defined facets, with a few isolated patches of intergranular cracking. Two types of slip offsets are observed: wavy offsets are superimposed on dimple walls and planar offsets are sometimes found on steeply inclined facets. Finding both wavy and planar slip offsets under rapid loading conditions, whereby hydrogen cannot diffuse, indicates that a hydrogen content of about 70 ppm is the critical amount to initiate a transition from homogeneous to heterogeneous slip.

The high $K_{p_{\max }}$ values observed under rapid loading conditions indicate that $65 \mathrm{ppm}$ hydrogen in Alloy 690 and 70 ppm hydrogen in EN52 is insufficient to severely embrittle these materials, but these levels produce the first signs of intergranular cracking and crystallographic faceting. Apparently, higher local hydrogen concentrations are developed within the crack tip region in slowly loaded specimens.

The critical local hydrogen concentrations required for LTCP can be estimated from the slow test of the precharged specimens by assuming that there is sufficient time for hydrogen to diffuse and accumulate ahead of the crack. Under equilibrium conditions, local hydrogen concentrations are estimated using the relationship: ${ }^{(17)}$

$$
\frac{C}{C_{0}}=\exp \frac{\sigma_{H} \bar{V}}{R T}
$$

where: $\quad C=$ local hydrogen concentration

$\mathrm{C}_{\mathrm{o}}=$ bulk hydrogen concentration

$\sigma_{\mathrm{H}}=$ hydrostatic stress

$\bar{V}=$ partial molar volume of hydrogen in solid solution

$\mathrm{R}=$ universal gas constant

$T=$ absolute temperature 
$\bar{V}$, defined as the change in volume produced by the addition of $1 \mathrm{gram}$-mol of hydrogen into a metal, is estimated to be $1.8 \mathrm{~cm}^{3} / \mathrm{mol}$ based on lattice parameter measurements for solutions of hydrogen in nickel and other face-centered cubic metals. ${ }^{18.19)}$ The peak hydrostatic stress is estimated from References (20) and (21), which reported that the peak stress ahead of a crack in high strain hardening materials is about five times the yield strength. Assuming plane strain conditions, the peak hydrostatic stress is about $\mathbf{5 0 \%}$ of the peak normal stress or $\mathbf{2 . 5}$ times the yield strength.

Based on Equation (4), the peak C/Co ratios at $24^{\circ} \mathrm{C}$ are 1.8 for Alloy $690\left(\sigma_{y s}=345\right.$ $\mathrm{MPa})$ and 2.2 for EN52 $\left(\sigma_{\mathrm{v} z}=415 \mathrm{MPa}\right)$. Therefore, peak hydrogen concentrations for the precharged specimens that were slowly loaded in air were calculated to be $\sim 120 \mathrm{ppm}$ for Alloy 690 and $\sim 160$ ppm for EN52. Because these specimens showed essentially the same degree of embrittlement as that observed for non-precharged specimens tested in $54^{\circ} \mathrm{C}$ water, critical lattice hydrogen concentrations to produce LTCP are estimated to be in the range of 120 to $160 \mathrm{ppm}$. This assumes that cracking events nucleate near the peak triaxial stress location.

In summary, local hydrogen concentrations of about $70 \mathrm{ppm}$ induce the first signs of intergranular cracking, but are insufficient to cause significant embrittlement. Full grain embrittlement occurs at approximately 120 to $160 \mathrm{ppm}$, which agrees with EN82H weld findings where the critical hydrogen content to cause LTCP was estimated to be $130 \mathrm{ppm} .{ }^{(8)}$ It is noted that hydrogen concentrations at grain boundaries are actually higher than those levels for the surrounding lattice because grain boundaries and grain boundary carbides serve as effective hydrogen traps. 


\section{CONCLUSIONS}

The fracture toughness of Alloy 690 and EN52 welds was characterized in $24^{\circ}$ to $338^{\circ} \mathrm{C}$ air and water with $150 \mathrm{cc} \mathrm{H}_{2} / \mathrm{kg} \mathrm{H}_{2} \mathrm{O}$. The results of this work are provided below.

1. The excellent fracture toughness displayed by Alloy 690 and EN52 in air and elevated temperature water demonstrates that fracture is not an issue under these conditions.

2. The fracture resistance of both materials is dramatically reduced in $54^{\circ} \mathrm{C}$ water, as $\mathrm{J}_{\mathrm{IC}}$ and tearing moduli are reduced by one to two orders of magnitude. Low temperature fracture is not viewed as a primary engineering concern for Alloy 690 because some plastic deformation precedes cracking and a modest tearing resistance is retained. Some welds show little or no plasticity prior to cracking and tearing moduli as low as 4 , so fracture is a potential concern in low temperature water.

3. Because LTCP in the most embrittled welds initiates within the linear-elastic domain, the lower-bound $\mathrm{K}_{\text {fmax }}$ of $53 \mathrm{MPa} / \mathrm{m}$ can be used in fracture mechanics evaluations to assess structural integrity of welded components.

4. Increasing the water temperature to $93^{\circ} \mathrm{C}$ and above significantly improves cracking resistance in both Alloy 690 and EN52; hence, LTCP is not a concern above this temperature.

5. Low temperature cracking is not an issue for short-term transients where loading rates exceed $25,000 \mathrm{MPa} / \mathrm{m} / \mathrm{h}$ because there is insufficient time for embrittlement to occur. For EN52 weld, a modest increase in cracking resistance is observed at $1300 \mathrm{MPa} / \mathrm{m} / \mathrm{h}$.

6. The toughness degradation displayed by Alloy 690 and EN52 in $54^{\circ} \mathrm{C}$ water is attributed to a hydrogen-induced intergranular cracking mechanism. Hydrogen from the water reduces grain boundary cohesive strength and promotes planar slip which localizes strain concentrations along grain boundaries. Results from hydrogen-precharged specimens indicate that the critical hydrogen content in the lattice to produce LTCP is on the order of 120 to $160 \mathrm{ppm}$. 
ACKNOWLEDGEMENT

This work was performed under U. S. Department of Energy Contract DE-AC1198PN38206 with Bettis Atomic Power Laboratory. The authors wish to acknowledge J. R. Suty, J. R Chalfant, S. A. Derry and R. D. Wineland for performing environmental tests and B. J. Whitmore and R. K. Ramaley for performing SEM fractographic examinations. Appreciation is also extended to $D$. M. Symons for the enlightening discussions. 


\section{REFERENCES}

(1) C. M. Brown and W. J. Mills, "Effect of Water on Mechanical Properties and Stress Corrosion Behavior of Alloy 600, Alloy 690, EN82H Welds and EN52 Welds," Corrosion, 1999 , in press.

(2) K. Norring, J. Engstrom and P. Norberg, "Intergranular Stress Corrosion Cracking in Steam Generator Tubing, Testing of Alloy 690 and Alloy 600 Tubes," Proceedings of the Third International Symposium on Environmental Degradation of Materials in Nuclear Power Systems--Water Reactors, TMS, 1988, pp. 587-593.

(3) R. G. Aspden, T. F. Grand and D. L. Harrod, "Corrosion Performance of Alloy 690," Proceedings: 1989 EPRI Alloy 690 Workshop, EPRI Report NP-6750-SD, April 1990.

(4) R. A. Page, "Stress Corrosion Cracking of Alloys 600 and 690 and Nos. 82 and 182 Weld Metals in High Temperature Water," Corrosion, Vol. 39, 1983, pp. 409-421.

(5) T. Yonezawa, K. Onimura, N. Sasaguri, T. Kusakabe, H. Nagano, K. Yamanaka, T. Minami and M. Inoue, "Effect of Heat Treatment on Corrosion Resistance of Alloy 690," Proceedings of the Second International Symposium on Environmental Degradation of Materials in Nuclear Power Systems--Water Reactors, ANS, 1986, pp. 593-600.

(6) P. Saint Paul and G. Slama, "Steam Generator Materials Degradation," Proceedings of the Fifth International Symposium on Environmental Degradation of Materials in Nuclear Power Systems--Water Reactors, ANS, 1992, pp. 39-49.

(7) A. S. O'Neill and J. F. Hall, "Literature Survey of Cracking of Alloy 600 Penetrations in PWR's," EPRI Report NP-7094, December 1990.

(8) C. M. Brown and W. J. Mills, "Fracture Toughness of Alloy 600 and EN82H Welds in Air and Water," B-T-3264, 1999. 
(9) W. J. Mills, "On the Relationship Between Stretch Zone Formation and the J Integral for High Strain-Hardening Materials," Journal of Testing and Evaluation, Vol. 9, 1981, pp. 56-62.

(10) P. C. Paris, H. Tada, A. Zahoor and H. Ernst, "The Theory of Instability of the Tearing Mode for Elastic-Plastic Crack Growth," Elastic-Plastic Fracture, ASTM STP 668, 1979, pp. 5-36.

(11) J. A. Begley and J. D. Landes, "The J Integral as a Fracture Criterion," Eracture Ioughness. Proceedings of the 1971 National Symposium on Fracture Mechanics. Part II, ASTM STP 514, 1972, pp. 1-20.

(12) W. C. Porr and W. J. Mills, "Application of the Normalization Data Analysis Technique for Single Specimen R-Curve Determination," Bettis Atomic Power Laboratory, Report, B-T-3269, February 1999.

(13) R. M. N. Pelloux, "Crack Extension by Alternating Shear," Engineering Fracture Mechanics, Vol. 1, 1970, pp. 697-704.

(14) C. W. Hunter, R. L. Fish and J. J. Holmes, "Channel Fracture in Irradiated EBR-II Type 304 Stainlesss Steel," Iransactions of the American Nuclear Society, Vol. 15, 1972, pp. 254-255.

(!5) W. J. Mills, "The Deformation and Fracture Characteristics of Inconel X-750 at Room Temperature and Elevated Temperatures," Metallurgical Transactions, Vol. 11A, 1980, pp. 1039-1047.

(16) E. A. Steigerwald, F. W. Schaller and A. R. Troiano, "The Role of Stress in Hydrogen Induced Delayed Failure," Iransactions of the AlME, Vol. 218, 1960, pp. 832-841

(17) W. W. Gerberich and Y. T. Chen, "Hydrogen-Controlled Cracking--An Approach to Threshold Stress Intensity," Metallurgical Transactions, Vol. 6A, 1975, pp. 271-278. 
(18) B. B. Baranowski, S. Majchrzak and T. B. Flanagan, "The Volume Increase of FCC Metals and Alloys Due to Interstitial Hydrogen Over a Wide Range of Hydrogen Contents," Journal of Physics F: Metal Physics, Vol. 1, 1971, pp. 258-261.

(19) M. L. Wayman and G. C. Smith, "Hydride Formation in Nickel-Iron Alloys," The Journal of Physics and Chemistry of Solids, Vol. 32, 1971, p. 103.

(20) J. R. Rice and M. A. Johnson, "The Role of Large Crack Tip Geometry Changes in Plane Strain Fracture," Inelastic Behavior of Solids, McGraw-Hill, NY, 1970, pp. 641-672.

(21) R. M. McMeeking, "Finite Deformation Analysis of Crack-Tip Opening in Elastic-Plastic Materials and Implications for Fracture," Journal of the Mechanics and Physics of Solids, Vol. 25, 1977, pp. 357-381. 


\begin{tabular}{|c|c|c|c|c|c|}
\hline \multicolumn{6}{|c|}{ Table 1 - Material Chemistries (weight percent) } \\
\hline Material & \multicolumn{2}{|c|}{ Alloy 690} & \multicolumn{3}{|c|}{ EN52 Welds } \\
\hline $\begin{array}{l}\text { Heat or } \\
\text { Weld }\end{array}$ & \multirow[t]{2}{*}{$\begin{array}{c}A^{n} \\
9486-3\end{array}$} & \multirow[t]{2}{*}{$\begin{array}{c}\text { “B” } \\
9518-1\end{array}$} & $\begin{array}{c}\text { "B1" } \\
\text { Y9378K }\end{array}$ & $\begin{array}{c}\text { "C1" } \\
\text { Y9378K }\end{array}$ & $\begin{array}{c}\text { "C2" } \\
\text { Y9378K }\end{array}$ \\
\hline $\begin{array}{c}\text { Shield } \\
\text { Gas }\end{array}$ & & & Ar & Ar & $\begin{array}{c}\text { Ar- } \\
2 \% \mathrm{H}_{2}\end{array}$ \\
\hline \multicolumn{6}{|l|}{ Element } \\
\hline C & 0.028 & 0.031 & 0.035 & 0.030 & 0.030 \\
\hline Mn & 0.31 & 0.05 & 0.26 & 0.25 & 0.25 \\
\hline $\mathrm{Fe}$ & 8.13 & 8.89 & 9.7 & 9.77 & 9.94 \\
\hline $\mathbf{S}$ & $<0.001$ & $<0.001$ & 0.001 & $<0.001$ & 0.001 \\
\hline $\mathrm{Si}$ & 0.032 & 0.032 & 0.28 & 0.17 & 0.21 \\
\hline $\mathrm{Cu}$ & 0.017 & 0.016 & 0.003 & 0.004 & 0.002 \\
\hline $\mathrm{Ni}$ & 61.28 & 60.61 & 58.55 & 58.96 & 58.8 \\
\hline $\mathrm{Cr}$ & 29.48 & 29.63 & 29.5 & 28.96 & 28.89 \\
\hline Al & 0.36 & 0.35 & 0.66 & 0.66 & 0.66 \\
\hline $\mathrm{Ti}$ & 0.32 & 0.34 & 0.56 & 0.50 & 0.55 \\
\hline$P$ & $<0.002$ & 0.002 & $<0.001$ & $<0.001$ & $<0.001$ \\
\hline $\mathrm{Nb}+\mathrm{Ta}$ & 0.003 & 0.002 & 0.004 & $<0.001$ & 0.002 \\
\hline
\end{tabular}




\begin{tabular}{|c|c|c|c|c|c|c|c|c|c|c|}
\hline \multicolumn{11}{|c|}{ Table 2 - Summary of Tensile Test Results } \\
\hline \multirow[b]{2}{*}{$\mathrm{T}$} & \multirow[b]{2}{*}{ Env } & \multirow[b]{2}{*}{ Prop } & \multicolumn{4}{|c|}{ EN52 } & \multicolumn{4}{|c|}{ Alloy 690} \\
\hline & & & $\bar{x}$ & $\mathbf{H}$ & $\mathbf{L}$ & $\mathbf{s}$ & $\bar{x}$ & $\mathrm{H}$ & $\mathbf{L}$ & $\mathbf{s}$ \\
\hline \multirow[t]{4}{*}{$338^{\circ} \mathrm{C}$} & \multirow[t]{4}{*}{ Water } & $\sigma_{\mathrm{ys}}(\mathrm{MPa})$ & 334 & 411 & 196 & 61 & 281 & 353 & 194 & 70 \\
\hline & & $\sigma_{\text {Urs }}(\mathrm{MPa})$ & 477 & 538 & 347 & 59 & 580 & 625 & 541 & 36 \\
\hline & & $\% \epsilon$ & 35.7 & 52.2 & 18.0 & 9.4 & 48.0 & 62.3 & 35.7 & 8.9 \\
\hline & & \%RA & 55.5 & 70.5 & 36.5 & 11.8 & 56.3 & 61.2 & 44.2 & 6.1 \\
\hline \multirow[t]{4}{*}{$54^{\circ} \mathrm{C}$} & \multirow[t]{4}{*}{ Water } & $\sigma_{\mathrm{Ys}}(\mathrm{MPa})$ & 414 & 463 & 308 & 48 & 255 & 268 & 234 & 14 \\
\hline & & $\sigma_{\text {urs }}(\mathrm{MPa})$ & 514 & 573 & 405 & 50 & 553 & 608 & 458 & 67 \\
\hline & & $\% \epsilon$ & 32.2 & 38.2 & 23.0 & 4.6 & 39.9 & 47.1 & 16.7 & 13.1 \\
\hline & & $\% \mathrm{RA}$ & 58.5 & 67.8 & 48.0 & 5.8 & 52.6 & 64.5 & 24.1 & 16.3 \\
\hline \multirow[t]{4}{*}{$338^{\circ} \mathrm{C}$} & \multirow[t]{4}{*}{ Air } & $\sigma_{\mathrm{YS}}(\mathrm{MPa})$ & 380 & 408 & 352 & 21 & 286 & 343 & 243 & 42 \\
\hline & & $\sigma_{\text {UTS }}(\mathrm{MPa})$ & 522 & 558 & 497 & 19 & 589 & 605 & 556 & 19 \\
\hline & & $\% €$ & 41.6 & 56.1 & 35.8 & 6.7 & 49.8 & 53.8 & 41.9 & 4.8 \\
\hline & & $\% \mathrm{RA}$ & 57.6 & 64.4 & 44.6 & 7.1 & 63.4 & 64.8 & 61.5 & 1.2 \\
\hline \multirow[t]{4}{*}{$54^{\circ} \mathrm{C}$} & \multirow[t]{4}{*}{ Air } & $\sigma_{\mathrm{Ys}}(\mathrm{MPa})$ & 441 & 483 & 418 & 23 & 311 & 407 & 266 & 59 \\
\hline & & $\sigma_{\text {UTS }}(\mathrm{MPa})$ & 588 & 632 & 527 & 34 & 631 & 647 & 603 & 21 \\
\hline & & $\% \in$ & 38.6 & 52.5 & 27.1 & 7.1 & 46.6 & 51.5 & 38.9 & 4.8 \\
\hline & & $\%$ RA & 57.9 & 67.1 & 46.1 & 6.9 & 63.3 & 65.9 & 60.1 & 2.1 \\
\hline \multirow[t]{4}{*}{$\mathrm{RT}$} & \multirow[t]{4}{*}{ Air } & $\sigma_{\mathrm{YS}}(\mathrm{MPa})$ & 454 & 492 & 395 & 37 & 321 & 393 & 279 & 46 \\
\hline & & $\sigma_{\text {uts }}(\mathrm{MPa})$ & 635 & 659 & 602 & 21 & 686 & 702 & 677 & 10 \\
\hline & & $\% \epsilon$ & 45.1 & 59.7 & 34.4 & 10.4 & 56.3 & 60.9 & 52.6 & 3.4 \\
\hline & & $\% \mathrm{RA}$ & 63.1 & 68.1 & 51.4 & 6.8 & 67.7 & 68.3 & 67.1 & 0.5 \\
\hline \multicolumn{11}{|c|}{$\begin{array}{l}\text { T - test temperature, ENV - test environment, } \\
\text { PROP - material properties: } \sigma_{\mathrm{YS}} \text { - yield strength, } \sigma_{\mathrm{UTS}} \text { - ultimate strength, } \% € \text { - percent elongation, } \\
\% \mathrm{RA} \text { - percent reduction in area } \\
\bar{x} \text { - average of all data, } H \text { - highest data point, } L \text { - lowest data point, } s \text { - standard deviation of data }\end{array}$} \\
\hline
\end{tabular}




\section{FIGURE CAPTIONS}

Figure 1. Representative microstructures for (a) Alloy 690 and (b) EN52 weld.

Figure 2. J-R curves for Alloy 690 Heat $A$ in air and water.

Figure 3. J-R curves for Alloy 690 Heat B in water.

Figure 4. Effect of displacement rate on the cracking behavior of Alloy 690 Heat B in water.

Figure 5. Fracture surface features for Alloy 690 tested in air and $338^{\circ} \mathrm{C}$ water were indistinguishable. (a) $338^{\circ} \mathrm{C}$ air. Duplex dimple morphology with large dimples nucleated by large carbide inclusions and smaller dimples nucleated by ghost boundary carbides. Note evidence of serpentine slip offsets and elongated shear dimples in the shear-stretch region (on right side). (b) $338^{\circ} \mathrm{C}$ water. Large and small dimples. (c) $338^{\circ} \mathrm{C}$ water. Typical shear-stretch region.

Figure 6. SEM fractographs of Alloy 690 tested in $54^{\circ} \mathrm{C}$ water showing intergranular cracking but no evidence of dimple rupture. (a) Intergranular cracking and poorly defined transgranular facets. (b) High magnification of upper right corner of (a) showing rough appearance of grain boundary walls. (c) Poorly defined transgranular facets.

Figure 7. J-R curves for EN52 weld 'B1' in air and water.

Figure 8. J-R curves for EN52 welds ' $\mathrm{C} 1$ ' and ' $\mathrm{C} 2$ ' in water.

Figure 9. Effect of displacement rate on the cracking behavior of EN52 welds ' $\mathrm{C} 1$ ' and ' $\mathrm{C} 2$ '.

Figure 10. Fracture surface features for EN52 welds tested in air and $338^{\circ} \mathrm{C}$ water were indistinguishable. (a) $54^{\circ} \mathrm{C}$ air. Dimples and shear-stretch region (upper right). (b) $338^{\circ} \mathrm{C}$ water. Dimples (left) and shear-stretch region (right).

Figure 11. SEM fractographs of EN52 welds tested in $54^{\circ} \mathrm{C}$ water. (a) Dominant intergranular cracking morphology surrounding island of transgranular faceting (bottom center). (b) Intergranular fracture surfaces were rather featureless.

Figure 12. $K_{p_{\max }}$ values for EN52 weld and Alloy 690. Non-precharged specimens were tested in $54^{\circ} \mathrm{C}$ air or water; hydrogen-precharged $[\mathrm{H}]$ specimens were tested in $24^{\circ} \mathrm{C}$ air or water. The short test times for the rapid loading tests [Rap], where maximum load was reached in 1 to 3 seconds, preclude hydrogen from diffusing to the crack tip. Crosshatching represents a range of $\mathrm{K}_{\mathrm{p}_{\max }}$ values.

Figure 13. Fracture surface morphology for hydrogen-precharged Alloy 690. (a) Tested in air. Intergranular cracking and transgranular faceting. (b) Tested in air. Crystallographic facets steeply inclined to fracture surface. (c) Tested in water. Intergranular cracking and transgranular faceting.

Figure 14. Fracture surface morphology for hydrogen-precharged EN52 welds. (a) Tested in air. Extensive intergranular cracking with small transgranular islands. (b) Tested in water. Fracture surface is predominantly intergranular. 


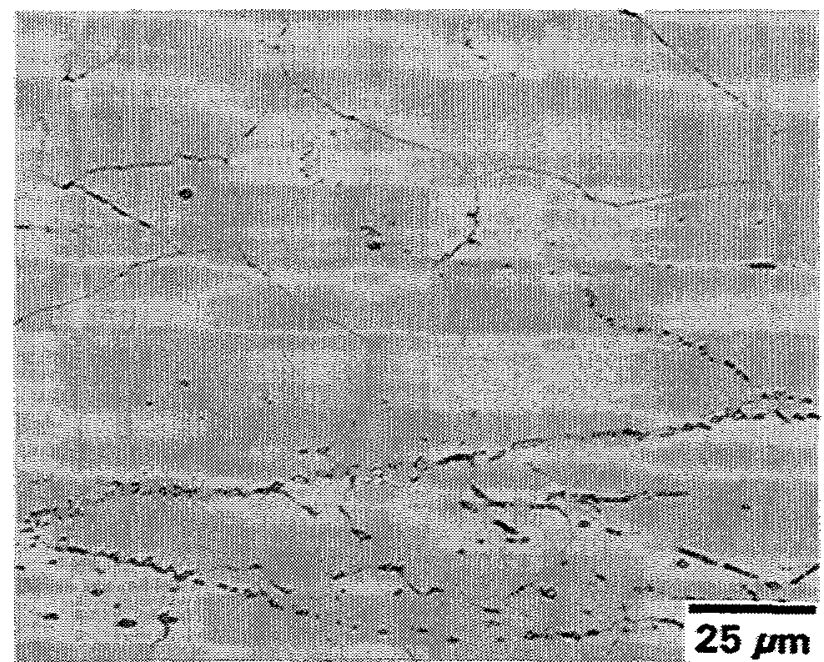

(a)

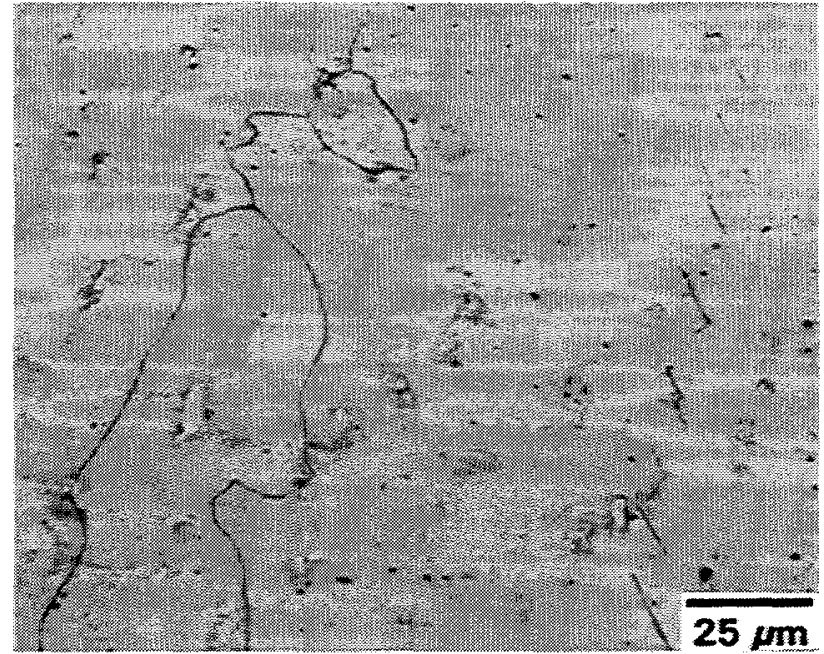

(b)

Figure 1. Representative microstructures for (a) Alloy 690 and (b) EN52 weld. 


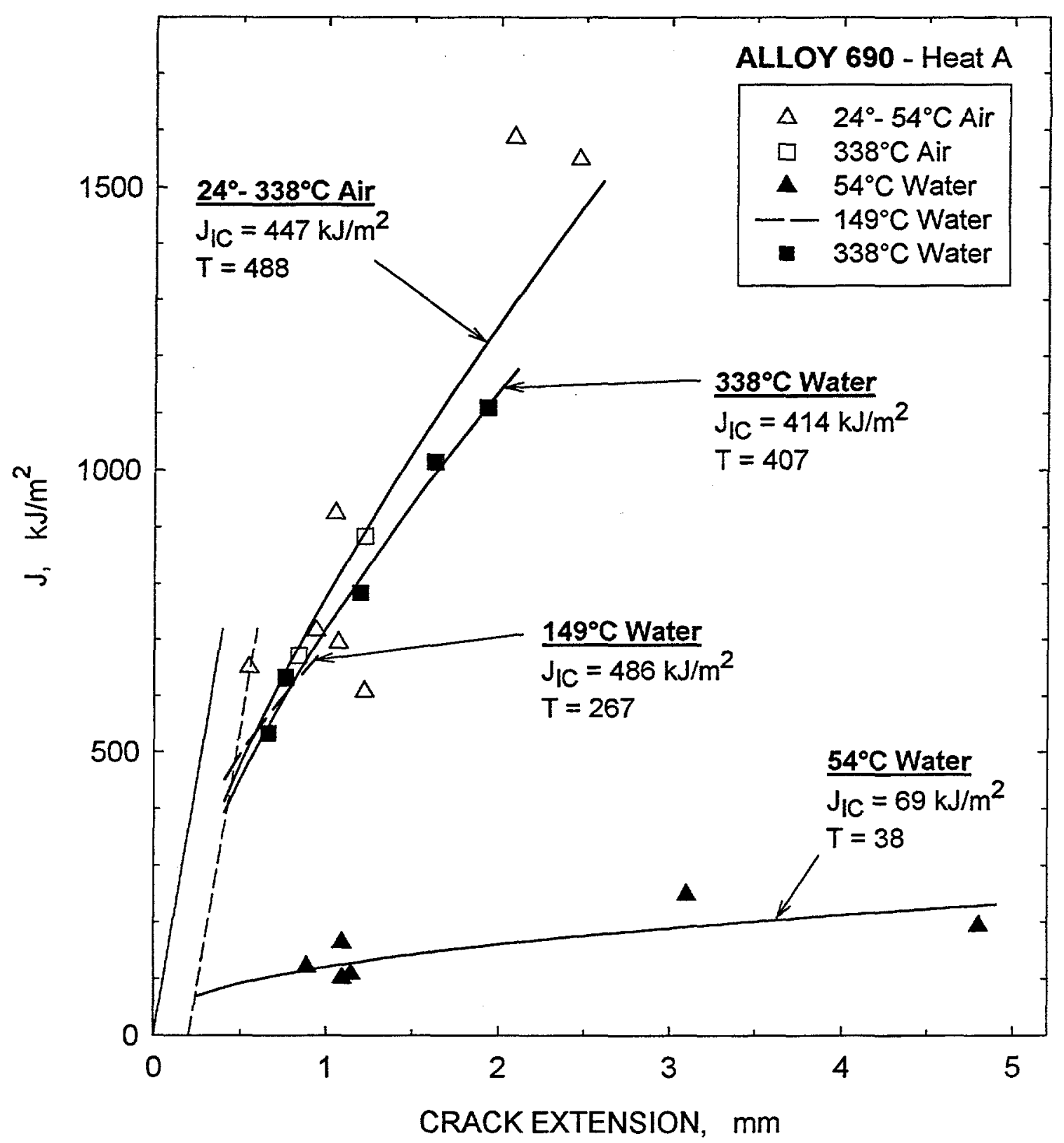

Figure 2. J-R curves for Alloy 690 Heat $A$ in air and water. 


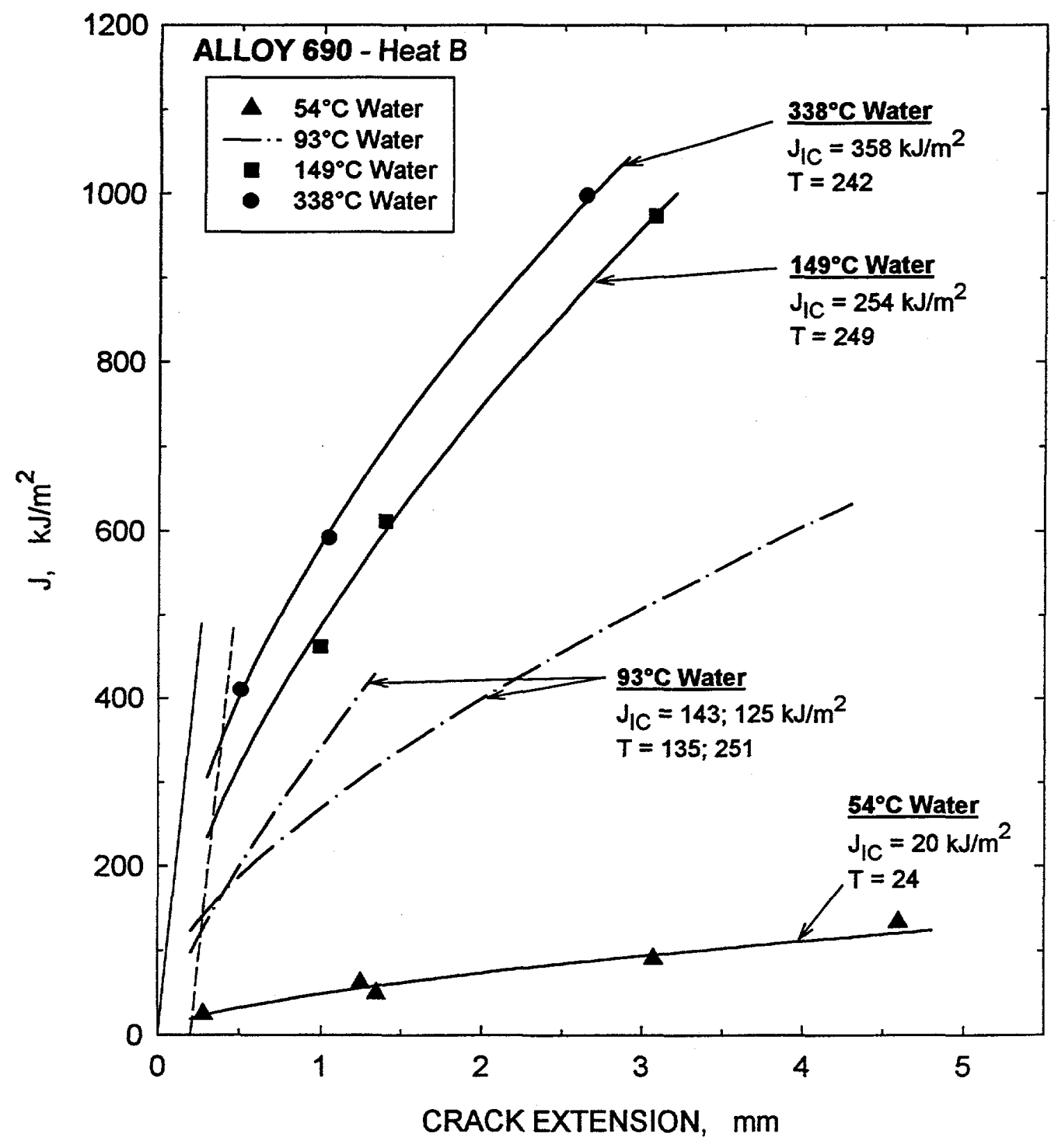

Figure 3. J-R curves for Alloy 690 Heat $B$ in water. 


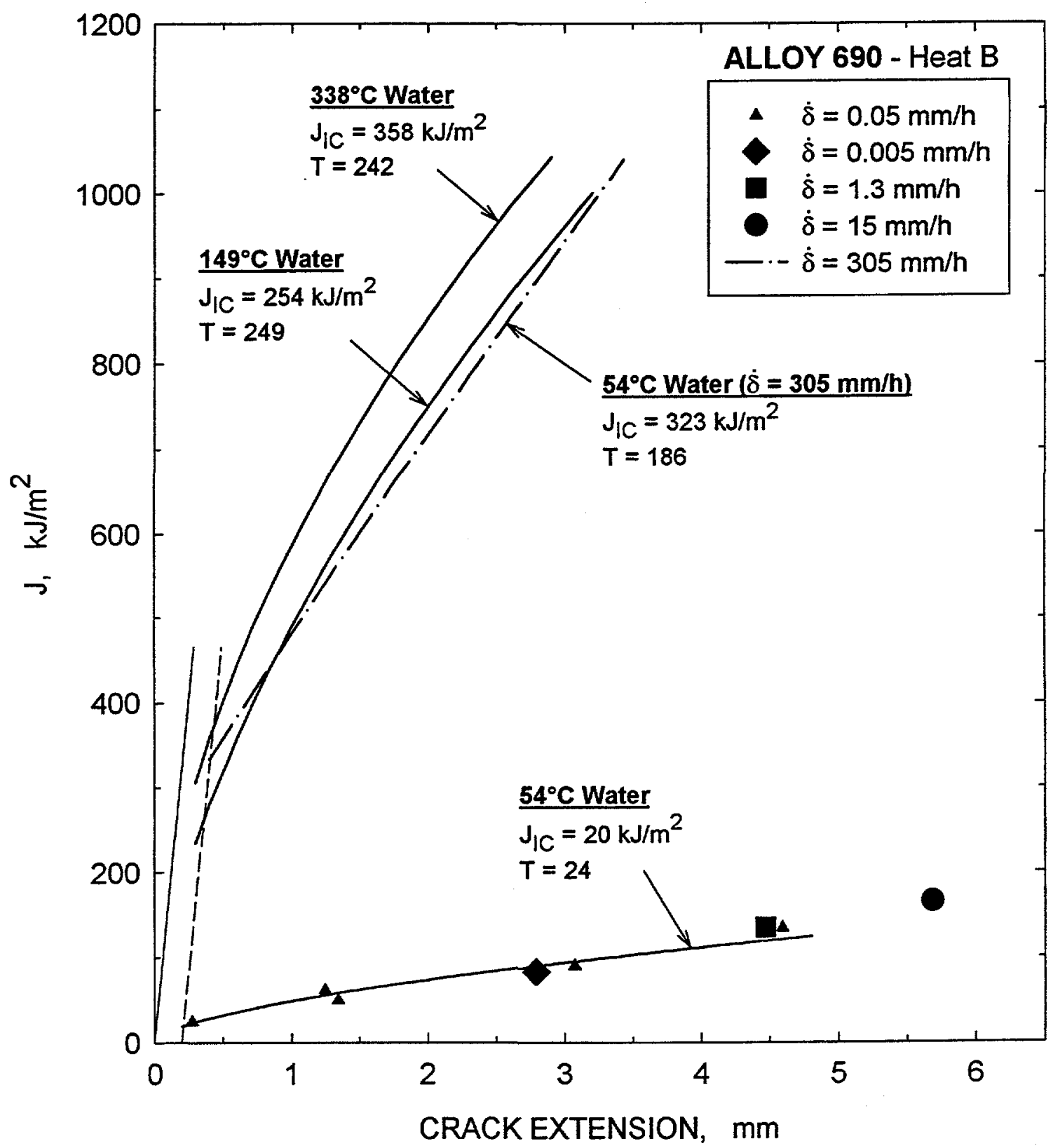

Figure 4. Effect of displacement rate on the cracking behavior of Alloy 690 Heat B in water. 


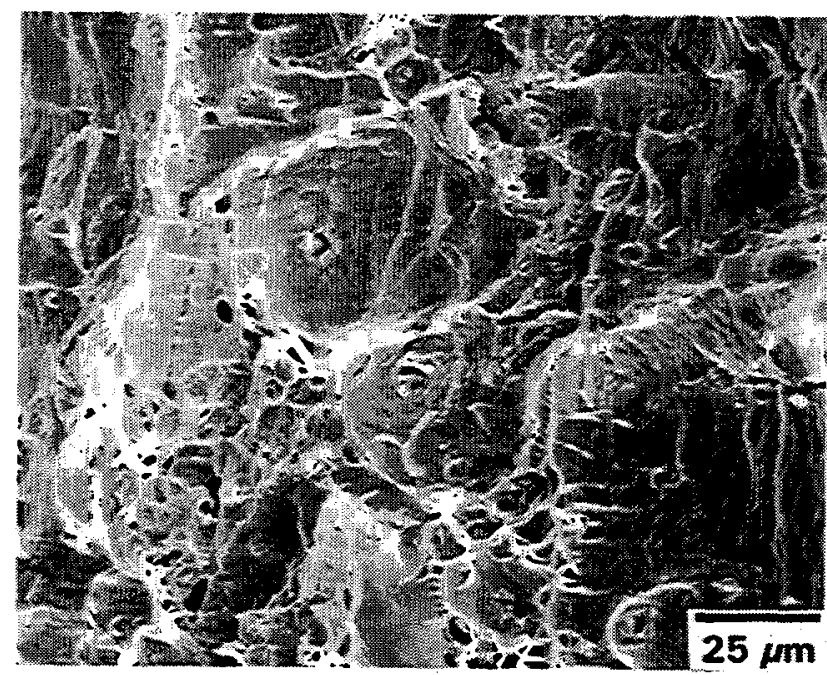

(a)

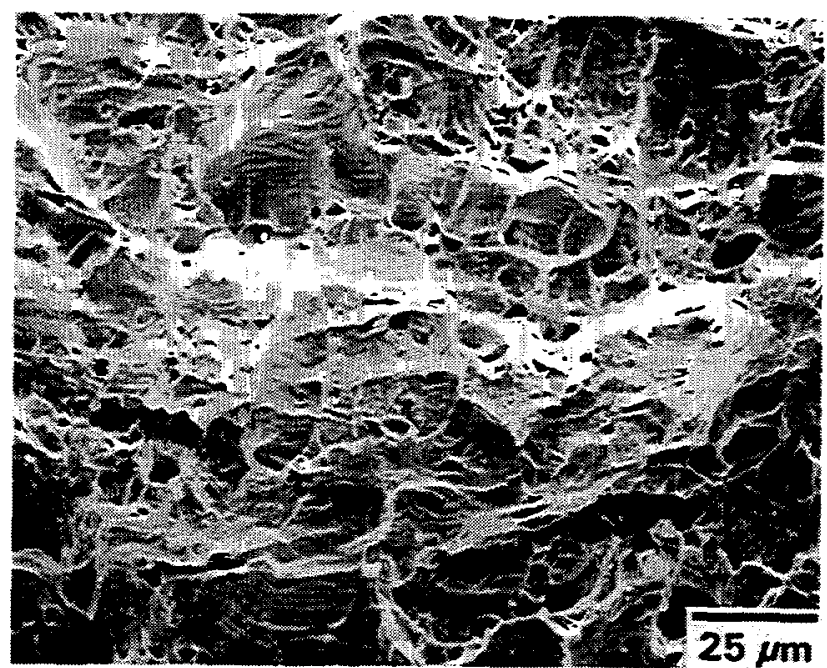

(b)

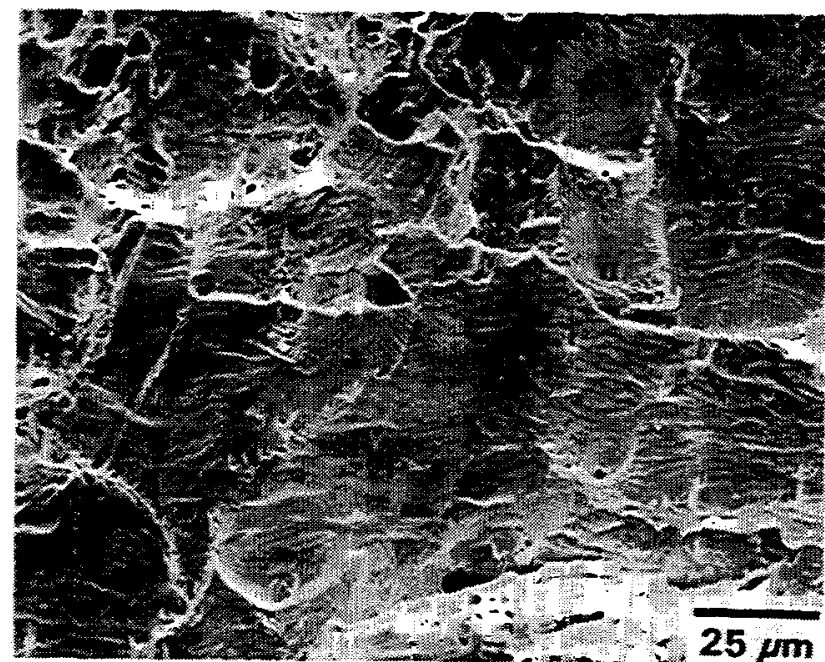

(c)

Figure 5. Fracture surface features for Alloy 690 tested in air and $338^{\circ} \mathrm{C}$ water were indistinguishable. (a) $338^{\circ} \mathrm{C}$ air. Duplex dimple morphology with large dimples nucleated by large carbide inclusions and smaller dimples nucleated by ghost boundary carbides. Note evidence of serpentine slip offsets and elongated shear dimples in the shear-stretch region (on right side). (b) $338^{\circ} \mathrm{C}$ water. Large and small dimples. (c) $338^{\circ} \mathrm{C}$ water. Typical shear-stretch region. 


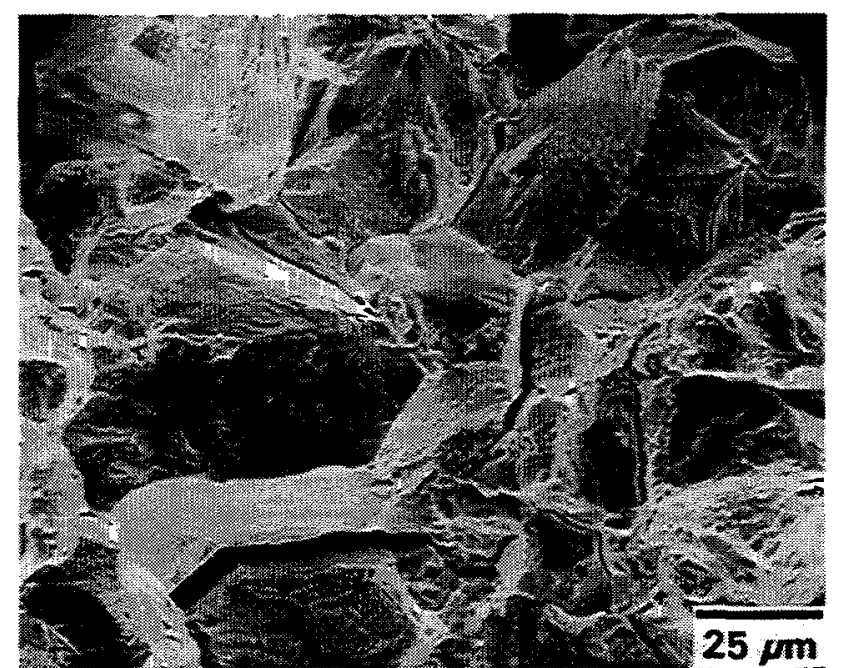

(a)

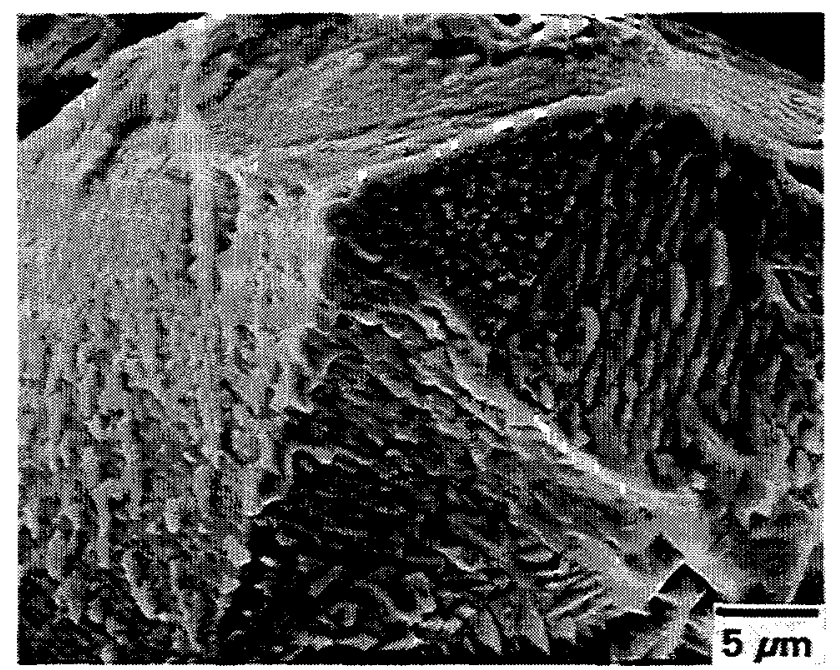

(b)

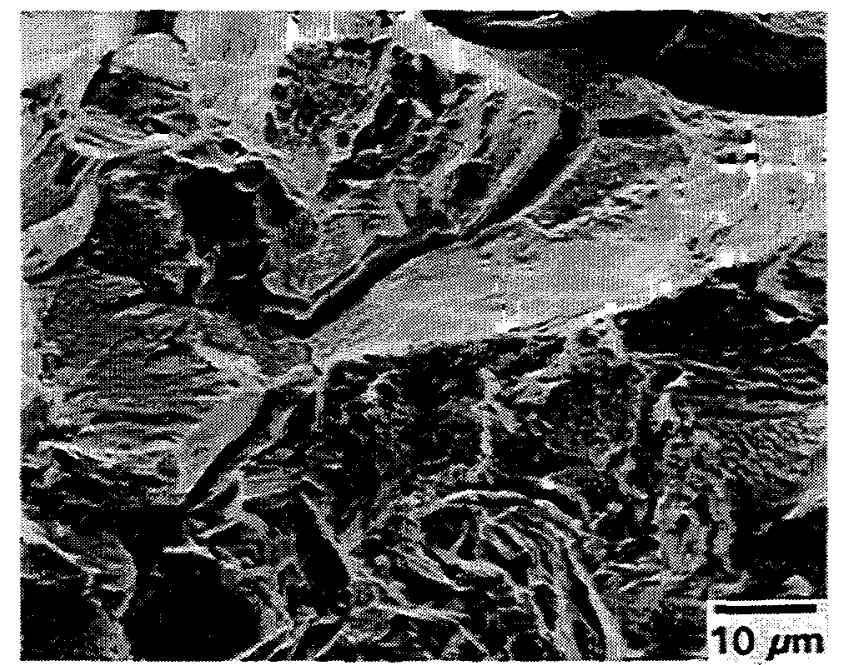

(c)

Figure 6. SEM fractographs of Alloy 690 tested in $54^{\circ} \mathrm{C}$ water showing intergranular cracking but no evidence of dimple rupture. (a) Intergranular cracking and poorly defined transgranular facets. (b) High magnification of upper right corner of (a) showing rough appearance of grain boundary walls. (c) Poorly defined transgranular facets. 


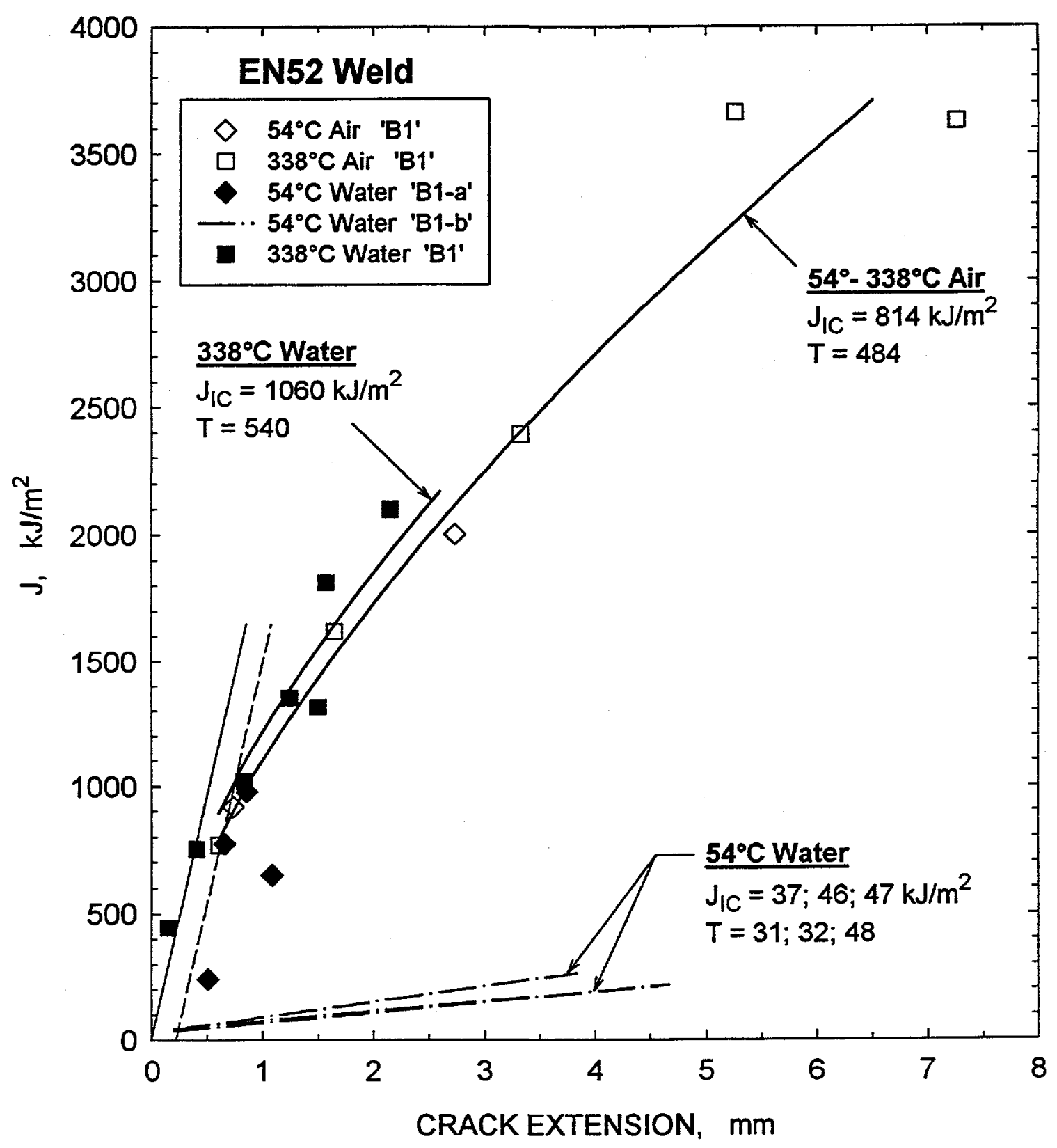

Figure 7. J-R curves for EN52 weld 'B1' in air and water. 


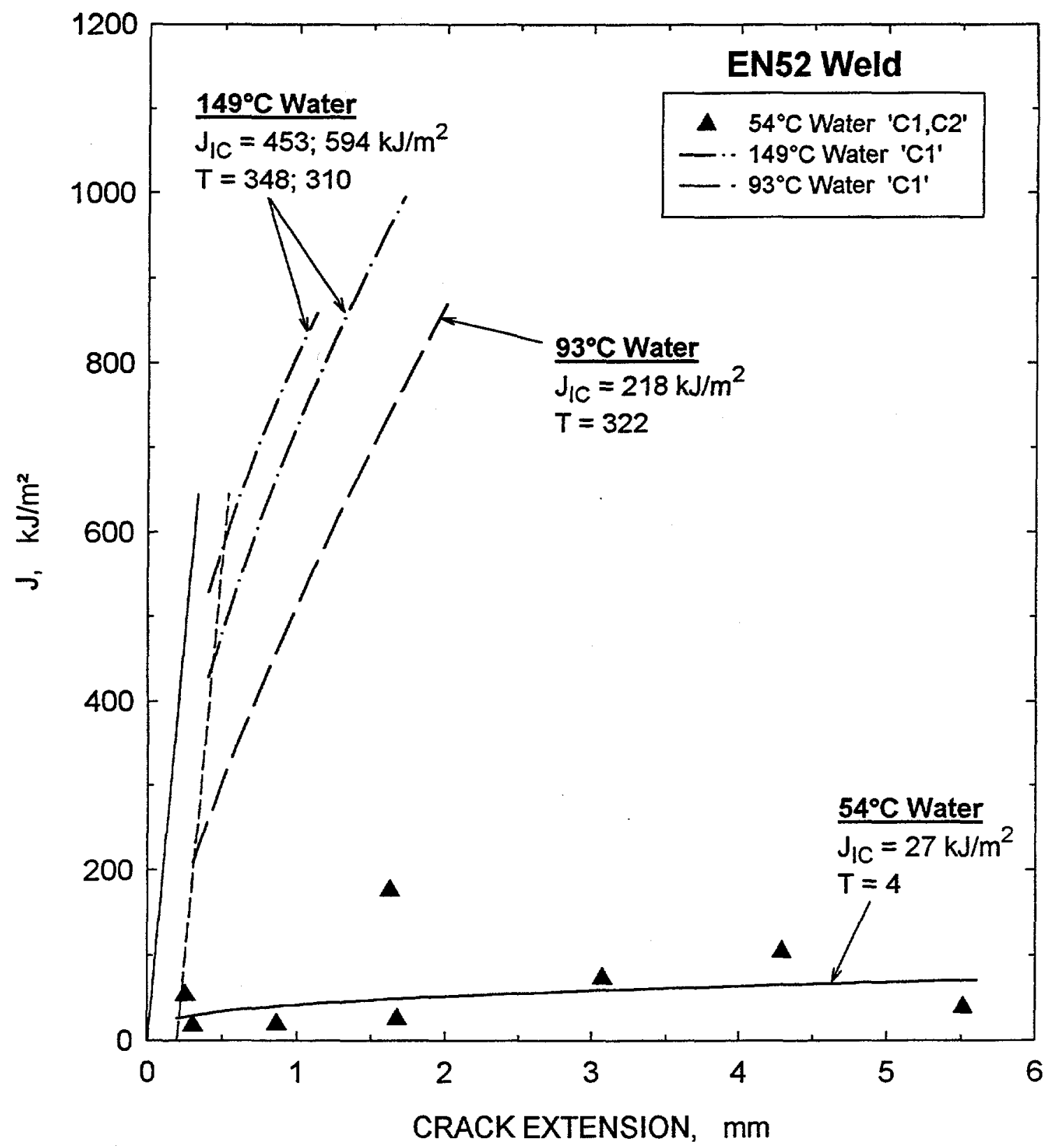

Figure 8. J-R curves for EN52 welds ' $\mathrm{C} 1$ ' and ' $\mathrm{C} 2$ ' in water. 


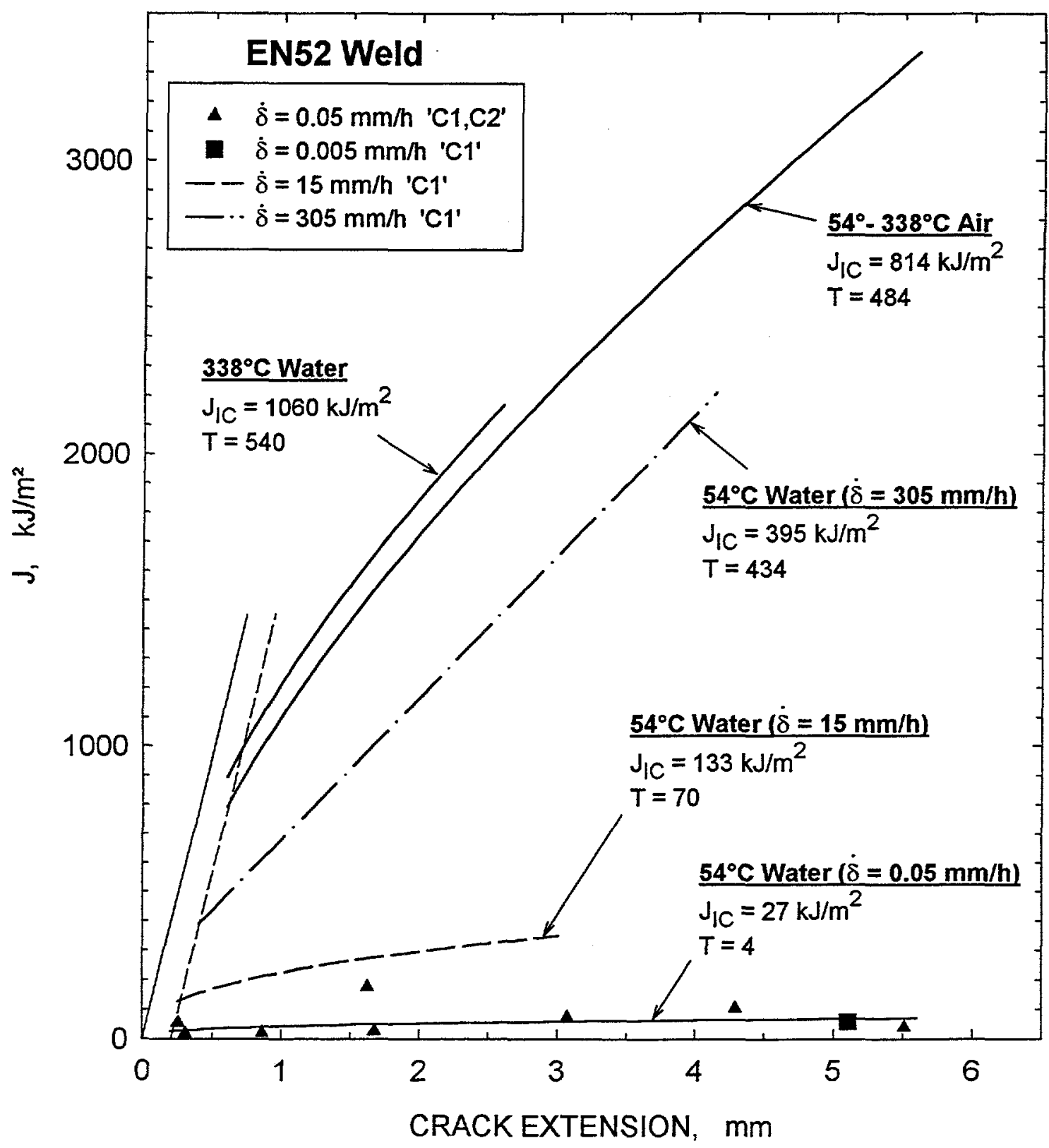

Figure 9. Effect of displacement rate on the cracking behavior of EN52 welds ' $\mathrm{C} 1$ ' and ' $\mathrm{C} 2$ '. 


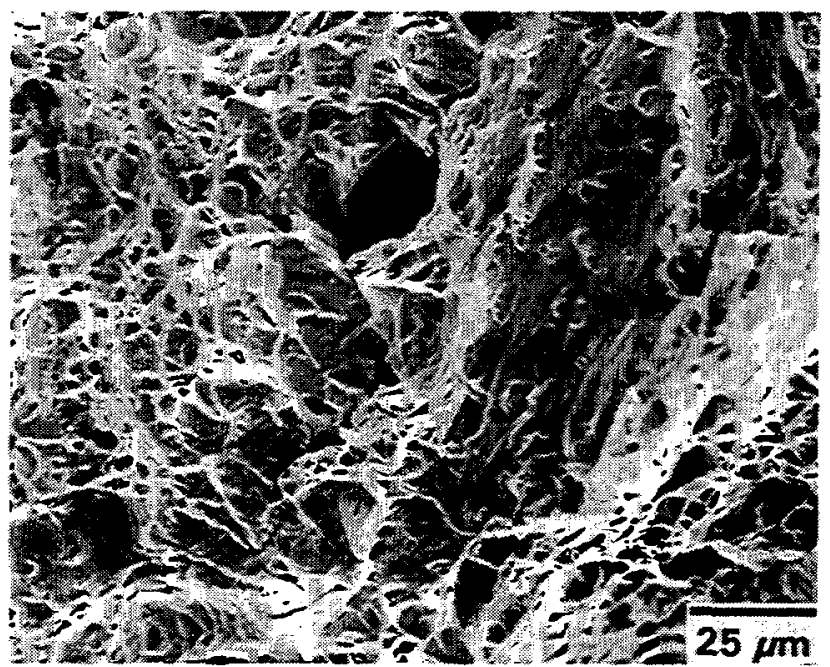

(a)

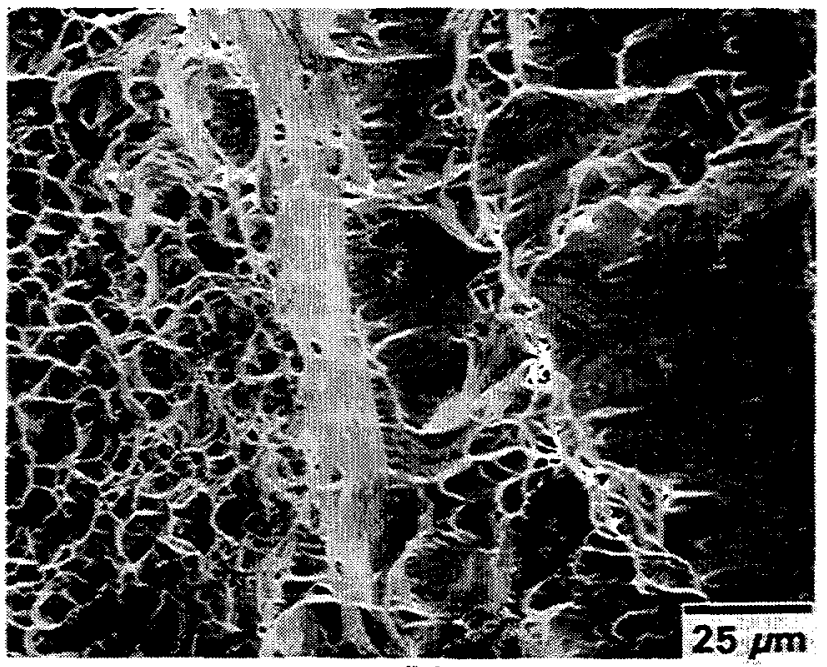

(b)

Figure 10. Fracture surface features for EN52 welds tested in air and $338^{\circ} \mathrm{C}$ water were indistinguishable. (a) $54^{\circ} \mathrm{C}$ air. Dimples and shear-stretch region (upper right). (b) $338^{\circ} \mathrm{C}$ water. Dimples (left) and shear-stretch region (right). 


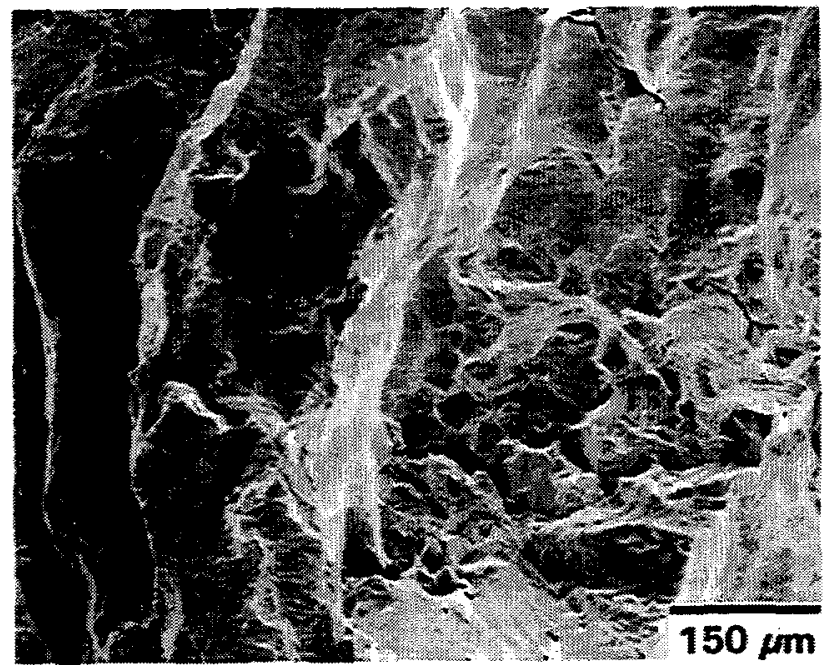

(a)

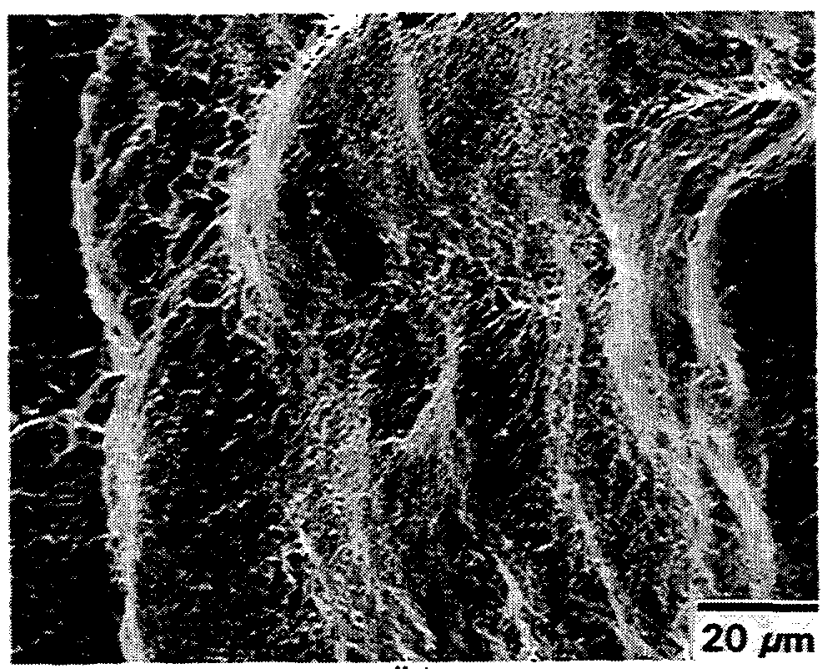

(b)

Figure 11. SEM fractographs of EN52 welds tested in $54^{\circ} \mathrm{C}$ water. (a) Dominant intergranular cracking morphology surrounding island of transgranular faceting (bottom center). (b) Intergranular fracture surfaces were rather featureless. 


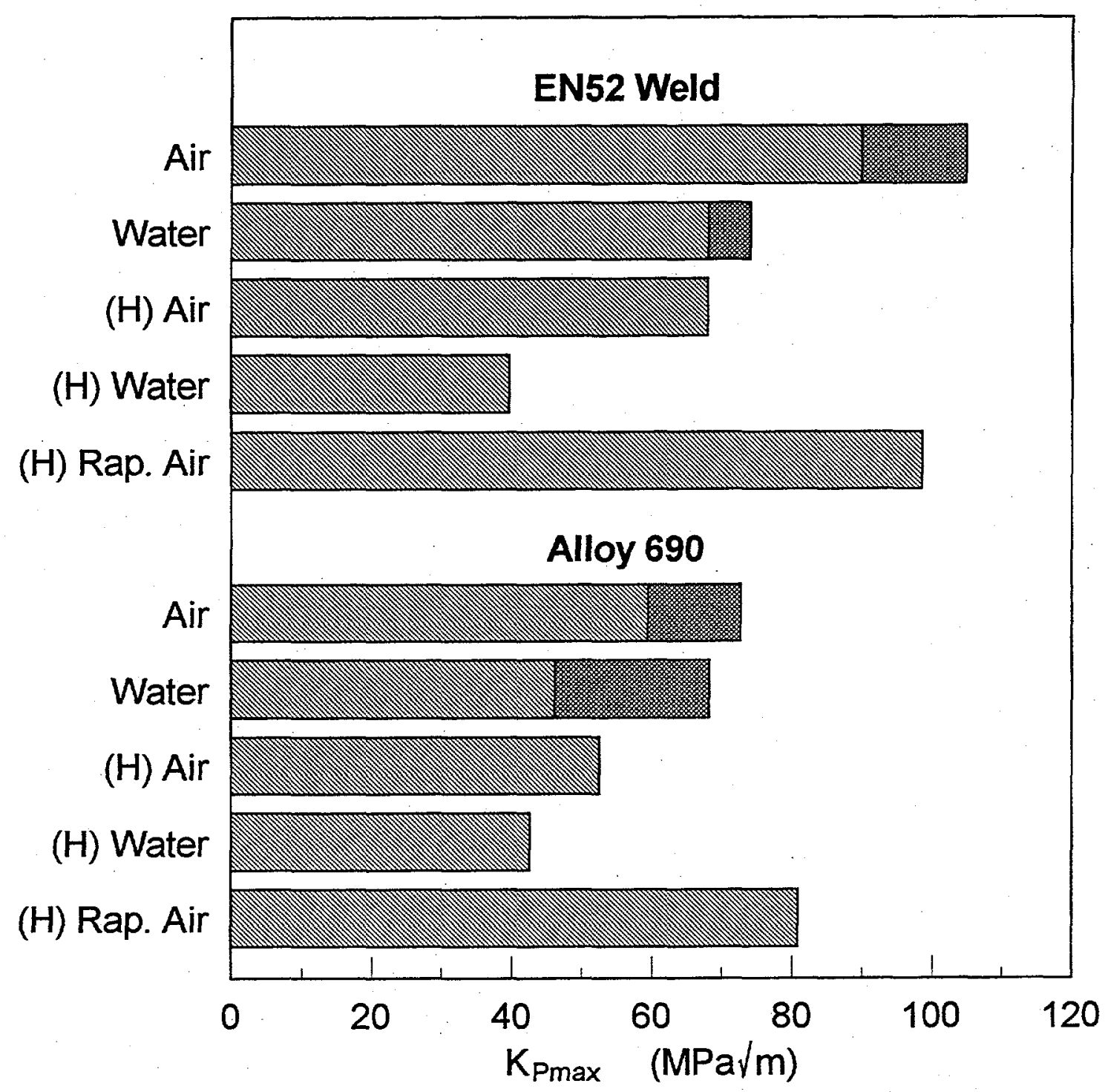

Figure 12. $\mathrm{K}_{\mathrm{Pmax}}$ values for EN52 weld and Alloy 690. Non-precharged specimens were tested in $54^{\circ} \mathrm{C}$ air or water; hydrogen-precharged $[\mathrm{H}]$ specimens were tested in $24^{\circ} \mathrm{C}$ air or water. The short test times for the rapid loading tests [Rap], where maximum load was reached in 1 to 3 seconds, preclude hydrogen from diffusing to the crack tip, so bulk hydrogen levels control fracture behavior. Crosshatching represents a range of $K_{P_{\max }}$ values. 


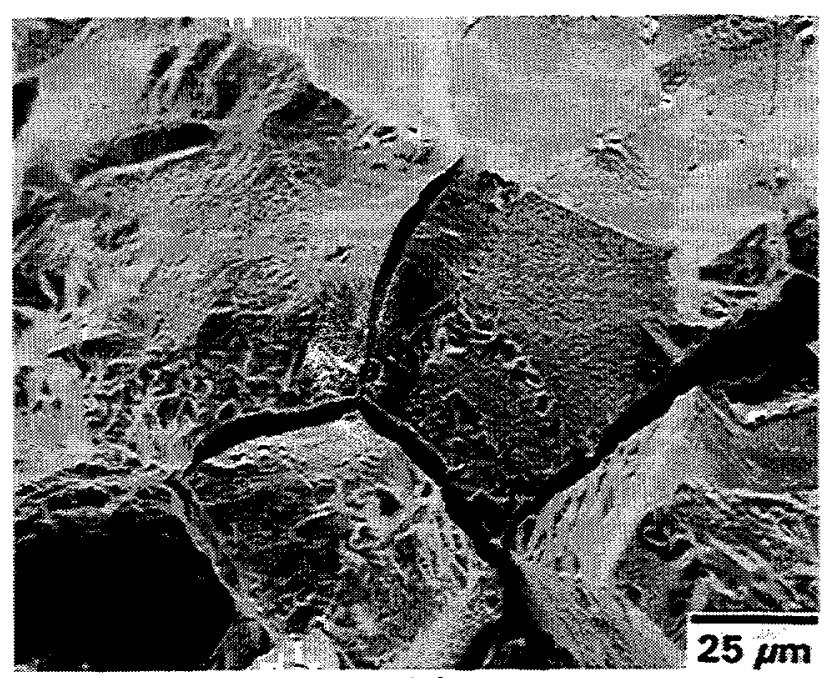

(a)

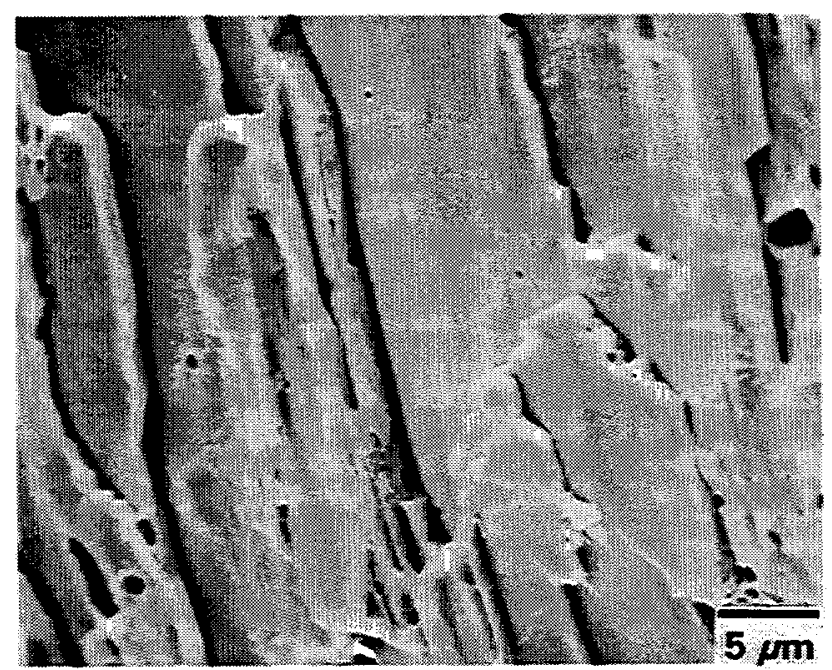

(b)

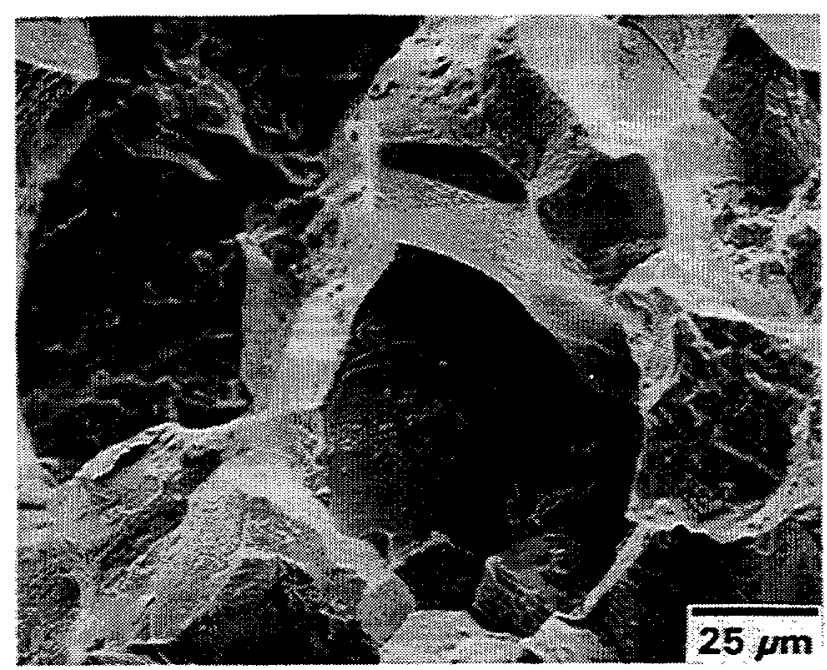

(c)

690FR3.cdr

Figure 13. Fracture surface morphology for hydrogen-precharged Alloy 690. (a) Tested in air. Intergranular cracking and transgranular faceting. (b) Tested in air. Crystallographic facets steeply inclined to fracture surface. (c) Tested in water. Intergranular cracking and transgranular faceting. 


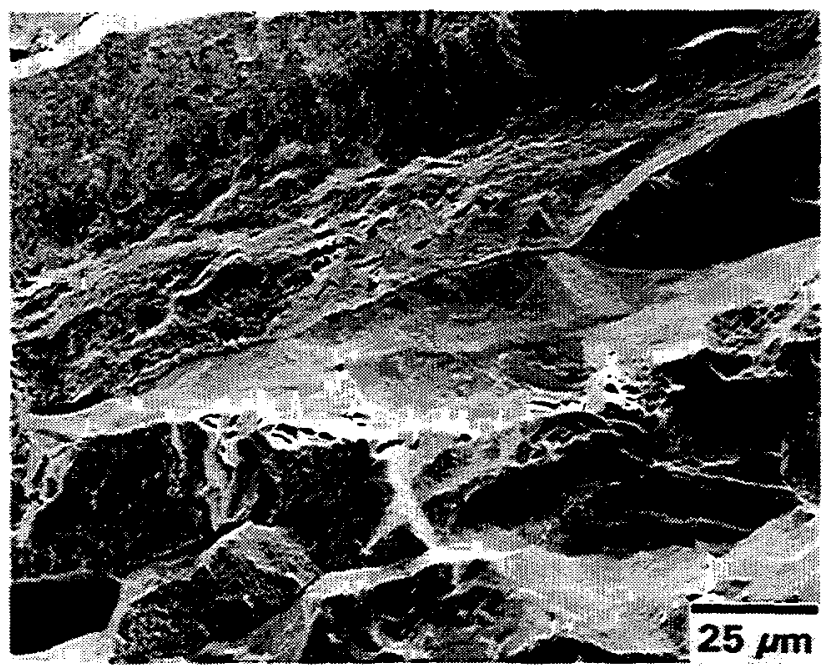

(a)

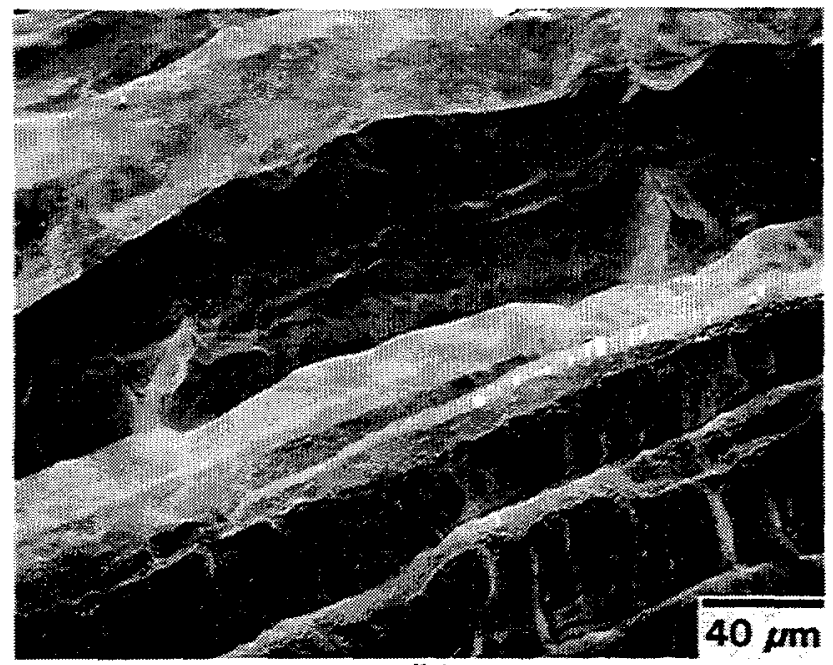

(b)

Figure 14. Fracture surface morphology for hydrogen-precharged EN52 welds. (a) Tested in air. Extensive intergranular cracking with small transgranular islands. (b) Tested in water. Fracture surface is predominantly intergranular. 